\title{
¿COOPERACIÓN O CONFLICTO? LAS RELACIONES EJECUTIVO-LEGISLATIVO EN EL SEXENIO DE FELIPE CALDERÓN
}

Rodrigo VelázQuez López Velarde

\section{INTRODUCCIÓN}

LA INTERACCIÓN ENTRE LOS PODERES ejecutivo y legislativo es de vital importancia para los sistemas presidenciales. El tipo de relación que tenga el presidente con la Asamblea o Congreso es determinante para la implementación de las acciones gubernamentales, pues muchas de éstas tienen que contar con el aval de los legisladores. Las iniciativas de ley impulsadas por el ejecutivo y refrendadas por el legislativo pueden modificar sustancialmente áreas completas de política pública como es la seguridad social o la política de seguridad brindada a los ciudadanos. Si existe cooperación entre los poderes y el Congreso aprueba las propuestas de ley, el presidente tendrá la oportunidad para implementar su plan de gobierno con relativa facilidad. Por el contrario, si el ejecutivo se enfrenta a una asamblea que bloquea sistemáticamente sus reformas, las acciones de gobierno podrán ser detenidas o ampliamente modificadas.

El principal objetivo de este artículo es evaluar algunos aspectos clave de la relación ejecutivo-legislativo durante la administración del presidente Felipe Calderón Hinojosa. Este sexenio es recordado principalmente en la opinión pública por haber obtenido la presidencia con un margen mínimo de diferencia, por la falta de reconocimiento de la izquierda a Felipe Calderón como presidente legítimo, por la guerra emprendida contra el crimen organizado y por la alta tasa delictiva durante su gestión. Aunque estos sucesos 
marcaron en gran medida la administración del político panista, existieron otras acciones y leyes impulsadas por el presidente de gran trascendencia para la vida política, económica y social del país. El artículo analiza cuáles fueron estas leyes, qué iniciativas del ejecutivo fueron rechazadas por el Congreso y qué decretos de ley fueron vetados. Asimismo se examina si algunos de los cambios constitucionales aprobados durante este periodo modificaron el equilibrio de poder en la relación entre el presidente y el Congreso.

Diversos estudios en la bibliografía en ciencia política establecen que ciertos factores institucionales y contextuales facilitan o dificultan la relación entre el ejecutivo y el legislativo. De esta manera, varios autores han argumentado que la forma de gobierno, el grado de fragmentación política y el control de la mayoría en el legislativo por el partido del presidente son variables que afectan la interacción entre el ejecutivo y el Congreso. El artículo evalúa si el marco institucional (sistema presidencial) y el contexto político (multipartidismo y gobiernos sin mayoría) tuvieron un efecto en la producción legislativa durante la gestión del presidente Calderón. El análisis indica que ni el sistema presidencial, el multipartidismo, ni la ausencia de mayoría del partido del presidente en el Congreso produjeron una parálisis legislativa pero sí dificultaron la aprobación de algunas reformas estructurales.

El artículo está organizado en cuatro partes. En la primera sección se discuten tres factores que determinan el grado de cooperación o conflicto entre los poderes ejecutivo y legislativo en los sistemas presidenciales. La segunda parte analiza dos elementos de suma importancia en la relación entre el presidente Calderón y el Congreso: la tasa de aprobación de la agenda legislativa del ejecutivo y las observaciones o vetos que el presidente realizó a los decretos aprobados por los legisladores. ${ }^{1}$ El tercer apartado exa-

${ }^{1}$ La relación entre el ejecutivo y el legislativo no se limita a las iniciativas aprobadas, modificadas o rechazadas entre estas instituciones; existen otras esferas en las que el presidente y los legisladores interactúan que también son de gran trascendencia. Entre los ámbitos de interacción de los dos poderes están el control y supervisión que ejerce el Congreso de la Unión sobre las políticas y programas públicos y la ratificación de nombramientos a funcionarios públicos y a tratados internacionales por al menos una de las cámaras del Congreso. Por limi- 
mina las reformas constitucionales propuestas y aprobadas por el Congreso y las legislaturas locales que modificaron la relación entre los poderes ejecutivo y legislativo. En la cuarta sección se apuntan tres factores que permitieron la aprobación de las reformas estruturales al inicio del sexenio del presidente Enrique Peña Nieto. Finalmente, el artículo hace un balance de la relación ejecutivo-legislativo durante el gobierno de Felipe Calderón considerando los elementos examinados y las expectativas teóricas al respecto.

\section{DETERMINANTES DE LA COOPERACIÓN Y CONFLICTO EN LAS RELACIONES EJECUTIVO-LEGISLATIVO}

En cualquier sistema presidencial democrático existe cooperación y tensión entre el ejecutivo y legislativo dado el alto grado de interdependencia entre los dos poderes. El grado de cooperación y tensión fluctúa en mayor o menor medida dependiendo de factores contextuales y de reglas institucionales. Tres factores determinan el nivel de entendimiento y conflicto entre el presidente y el Congreso: la separación de poder y de propósito, la composición partidaria en el Congreso y la responsabilidad compartida de ambos poderes en el proceso de las políticas públicas.

\section{Separación de poder y de propósito}

En su artículo sobre el efecto de las instituciones en las políticas públicas Mathew S. Shugart y Stephen Haggard establecen que, al contrario del parlamentarismo, en todo sistema presidencial por definición existe una separación de la estructura del poder gubernamental. ${ }^{2}$ Dicha separación se deriva de dos características

taciones de espacio, este artículo se centra en la aprobación de las iniciativas del presidente y las observaciones del ejecutivo a los decretos del Congreso de la Unión.

${ }^{2}$ Mathew S. Shugart y Stephen Haggard, "Institutions and Public Policy in Presidential Systems", en Stephan Haggard y Mathew D. McCubbins (eds.), Presidents, Parliaments, and Policy, Nueva York, Cambridge University Press, 2001, 
esenciales de los sistemas presidenciales: 1) el poder ejecutivo y legislativo tienen autoridad independiente debido a que cada uno es electo de manera separada, y 2) ninguna de estas instituciones puede disolver al otro ni acortar su periodo de gobierno. ${ }^{3}$ Dado que en los sistemas presidenciales la estructura del gobierno está dividida, la modificación del statu quo tiende a ser más difícil dado que cualquiera de los poderes (el presidente o el Congreso) puede bloquear las iniciativas del otro. ${ }^{4}$

La elección por separado del ejecutivo y legislativo también puede producir una separación de propósito la cual se refiere al hecho que en un sistema político pueden existir o conformarse diversos actores con intereses encontrados. Con frecuencia, estos actores poseen poder de veto y pueden obstruir los intentos por cambiar el statu quo. Una de las fuentes más comunes de la separación de propósito es cuando ningún partido político controla la presidencia y el Congreso (gobierno sin mayoría), o cuando un partido distinto al del presidente tiene mayoría parlamentaria (gobierno dividido). Asimismo, la separación de propósito se puede originar porque el ejecutivo y legislativo representan a electorados diferentes con distintas preferencias. Por ejemplo, mientras que el titular del ejecutivo llega al poder con el voto de un electorado

pp. 64-102. Aunque en el parlamentarismo el ejecutivo y legislativo están fusionados puede existir separación de poder. Por ejemplo, la estructura gubernamental se encontrará dividida en un parlamentarismo si éste tiene un sistema bicameral o federal. La existencia de una segunda cámara o un de un conjunto de unidades componentes de una federación pueden producir intereses encontrados que impidan o retrasen cambios en la legislación. Véase Gary W. Cox y Mathew McCubbins, "The Institutional Determinants of Economic Policy Outcomes", en Stephan Haggard y Mathew D. McCubbins (eds.), op. cit., pp. 21-63.

${ }^{3}$ Shugart y Haggard, "Institutions and Public Policy in Presidential Systems", en Haggard y McCubbins, op. cit., p. 64.

${ }^{4}$ En su importante texto de los años noventa, Linz argumentó que la separación de poderes de los sistemas presidenciales tiende a producir parálisis legislativa e inestabilidad política, las cuales pueden producir en última instancia el rompimiento del régimen democrático. Juan J. Linz, "Presidential or Parliamentary Government: Does It Make a Difference?”, en Juan J. Linz y Arturo Valenzuela (eds.), The Failure of Presidential Democracy, vol. 1: Comparative Perspectives, Baltimore, The Johns Hopkins University Press, 1994, pp. 3-90. 
nacional, los legisladores son electos por uno subnacional o local. ${ }^{5}$ Los intereses de estos electorados no siempre coinciden: en principio, el presidente vela por los intereses de todo el país y los legisladores representan a los votantes de sus distritos, circunscripciones o estados. La representación de distintos electorados puede originar diferencias y fricciones entre los poderes incluso cuando el partido del presidente tiene mayoría en el Congreso.

La separación de poder como la de propósito son dos factores clave que pueden afectar el grado de cooperación y conflicto entre los poderes ejecutivo y legislativo. En principio se espera que en los sistemas presidenciales en donde el ejecutivo no cuenta con una mayoría en el Congreso exista mayor dificultad para aprobar la agenda legislativa dada la separación de poder y de propósito existentes. Por el contrario, en sistemas presidenciales en las que el partido del presidente tiene el control del legislativo tenderá a haber mayor cooperación pues aunque existe la separación de poder, la de propósito es generalmente menor.

\section{Composición partidaria en el Congreso}

Un segundo factor que tiene efecto en las relaciones entre el presidente y el legislativo es la composición partidaria del Congreso o Asamblea. En los sistemas presidenciales bicamerales, si los resultados electorales en ambas cámaras del Congreso dan la mayoría al partido del presidente, la relación tenderá a ser más cooperativa ya que un solo partido tendrá mayoría en las dos instituciones. Este contexto político, llamado gobierno unificado, es propicio para que el titular del ejecutivo pase su agenda con menor resistencia que cuando la oposición controla el poder legislativo. En esta circunstancia, el partido funciona como un puente entre las

${ }^{5}$ Shugart y Haggard, op. cit. En el sistema electoral mexicano existe una excepción a esta regla: tanto el presidente como los 32 senadores de representación proporcional son electos por un electorado nacional. La regla para elegir a estos senadores es mediante una lista votada en una sola circunscripción nacional. Véase el artículo 56 de la Constitución Política de los Estados Unidos Mexicanos. 
instituciones (el ejecutivo y legislativo) para alcanzar los acuerdos y disminuir la rivalidad inherente entre los dos poderes. ${ }^{6}$

De acuerdo a Shugart y Haggard, un gobierno unificado donde el partido del presidente es altamente disciplinado puede producir una unidad de propósito extrema, pues el ejecutivo podrá pasar su agenda sin mayor objeción. Un alto grado en la unidad de propósito puede tener efectos excluyentes ya que el partido en el gobierno no requiere de ningún apoyo de la oposición para la aprobación de la agenda legislativa. ${ }^{7}$ No obstante, la evidencia empírica muestra que el tener un gobierno unificado no garantiza una relación tersa entre los dos poderes, ni que el presidente podrá pasar todas sus iniciativas sin mayor problema. Aun con gobierno unificado, puede haber diferencias entre estos dos poderes -al menos en algunas áreas de política pública-, porque, como se mencionó anteriormente, cada uno representa intereses distintos. Basta recordar el fracaso del presidente Clinton al intentar pasar su iniciativa de reforma al sector salud al inicio de su mandato: el mandatario estadounidense fue incapaz de conseguir los votos suficientes en el Congreso a pesar de contar con una mayoría demócrata en ambas cámaras. En el caso mexicano, algunas reformas importantes como la laboral, fiscal y energética permanecieron estancadas por muchos años, aun cuando el Partido Revolucionario Institucional (PRI) contó con mayorías en el Congreso hasta 1997. Según algunos analistas, el estancamiento en estas iniciativas se debió a que algunos grupos dentro del PRI no estaban de acuerdo con los cambios propuestos por el presidente. ${ }^{8}$ Estos y otros ejemplos ilustran que aunque contar con una mayoría en el Congreso es muy importante, el éxito del ejecutivo para pasar su agenda no depende únicamente de los escaños en el poder legislativo, sino

${ }^{6}$ James L. Sundquist, "Needed: A Political Theory for the New Era of Coalition Government in the United States”, Political Science Quarterly, vol. 103, núm. 4, invierno 1988-1989, p. 629.

${ }^{7}$ Shugart y Haggard, op. cit., p. 65.

${ }^{8}$ Véase Eric Magar y Vidal Romero, "El impasse mexicano en perspectiva”, Foreign Affairs en Español, vol. 7, núm. 1, 2007, pp. 117-131; María Amparo Casar, "Quince años de gobiernos sin mayoría en el Congreso mexicano", Política y Gobierno, vol. 20, núm. 2, 2013, p. 239. 
también de otros factores como la cohesión interna y el nivel de disciplina partidaria que pueda ejercer sobres sus correligionarios.

Por otra parte, cuando el titular del ejecutivo no cuenta con un respaldo mayoritario en una o ambas cámaras del Congreso, el potencial para la parálisis legislativa se incrementa al menos en algunas áreas de política pública. Los gobiernos divididos han sido caracterizados por un alto conflicto entre las fuerzas políticas que tiende a suscitar estancamiento, retraso o indecisión en el Congreso. Con gran frecuencia, según algunos analistas como Sundquist, el gobierno dividido produce políticas inadecuadas o inefectivas. ${ }^{9}$ $\mathrm{Al}$ respecto, V. O. Key observó que en el sistema político estadounidense "el control partidario común del ejecutivo y legislativo no asegura un gobierno activo, pero la división del control partidario lo descarta". ${ }^{10}$

A pesar de estas observaciones, la discusión sobre el tema no ha establecido una conclusión definitiva sobre los efectos del gobierno dividido. El pionero en probar empíricamente el impacto de este fenómeno en la producción legislativa fue David Mayhew. Este autor no encuentra ninguna diferencia significativa en la tasa de aprobación legislativa entre los gobiernos unificados y divididos en Estados Unidos entre 1946 y 2002. ${ }^{11}$ El trabajo de Mayhew motivó la realización de múltiples estudios que ahondaron en las consecuencias de los gobiernos divididos en la producción, y encontraron resultados mixtos. ${ }^{12}$ Otros politólogos han ido más allá

${ }^{9}$ Según este argumento, los partidos bajo un contexto de gobierno dividido tienden a modificar sustancialmente sus preferencias para aprobar la legislación. El cambio en las preferencias produce problemas en el proceso de la implementación, pues ni el presidente ni el Congreso se comprometen a cumplir plenamente con lo aprobado ni se hacen responsables por la legislación adoptada. Sundquist, op. cit. p. 630.

10 Valdimer Orlando Key, Politics, Parties, and Pressure Groups, Nueva York, Thomas Y. Crowell Company, 1964, p. 688.

${ }^{11}$ David R. Mayhew, Divided We Govern: Party Control, Lawmaking, and Investigations 1946-2002, New Haven, Yale University Press, 2005.

12 Véase por ejemplo, Sean Q. Kelly, "Divided We Govern? A Reassessment, Polity, vol. 25, núm. 3, 1993, pp. 475-484; Charles O. Jones, The Presidency in a Separated System, Washington, D. C., Brookings Institution, 1994, pp. 196-201; William Howell, Scott Adler, Charles Cameron y Charles Riemann, "Divided Government 
del argumento de Mayhew afirmando que aun cuando no hay mayor diferencia entre el gobierno unificado y el dividido en términos de producción legislativa, un mayor número de propuestas de ley de gran envergadura iniciadas por el ejecutivo no pasan, permanecen estancadas o tienden a ser más moderadas cuando el partido del presidente no cuenta con una mayoría en el Congreso. ${ }^{13}$ La amplia investigación en este tema revela que la parálisis legislativa no sólo depende del número de escaños con los que cuente el presidente, sino también de otros factores institucionales, de condiciones políticas, así como de la capacidad de liderazgo de los actores relevantes involucrados. ${ }^{14}$ Entre estos factores está el sistema electoral. De acuerdo con este argumento institucionalista, si el presidente y los legisladores responden a un electorado nacional, habrá más incentivos para que estos dos actores lleguen a consensos, pues se espera que la ciudadanía responsabilice a los dos por la falta de acuerdo. Por el contrario, si el presidente responde a un electorado nacional y los legisladores a sus estados y distritos, habrá más riesgo de que se ocasione un conflicto entre los poderes en algunos temas de política pública, pues cada actor buscará satisfacer distintos intereses. El nivel de polarización política entre

and the Legislative Productivity of Congress 1945-1994", Legislative Studies Quarterly, vol. 25, núm. 2, 2000, pp. 285-312; James R. Rogers, "The Impact of Divided Government on Legislative Production”, Public Choice, vol. 123, núms. 1-2, 2005, pp. 217-233; Valerie Heitshusen y Garry Young, "Macropolitics and Changes in the U.S. Code: Testing Competing Theories of Policy Production, 1874-1946”, en E. Scott Adler y John S. Lapinski (eds.), The Macropolitics of Congress, Princeton, Princeton University Press, 2006, pp. 129-150.

13 Martha Gibson, "Politics and Divided Government", artículo presentado en reunión anual de la American Political Science Association, Nueva York, 1994; George C. Edwards III, Andrew Barrett y Jeffrey Peake, "The Legislative Impact of Divided Government”, American Journal of Political Science, vol. 41, núm. 2, 1997, pp. 545-563; Jeffrey E. Cohen, The President's Legislative Policy Agenda 1789-2002, Nueva York, Cambridge University Press, 2012. Para el caso mexicano véase Casar, "Quince años de gobiernos sin mayoría en el Congreso mexicano", op. cit.; Carlos Elizondo, Por eso estamos como estamos, México, Debate, 2011.

14 Véase Sarah A. Binder, "Legislative Productivity and Gridlock", en Eric Schickler y Frances E. Lee (eds.), The Oxford Handbook of American Congress, Nueva York, Oxford University Press, 2011, pp. 641-660; Casar, "Quince años de gobiernos sin mayoría en el Congreso mexicano”, op. cit., pp. 222-226. 
los partidos políticos también es una variable que determina la parálisis legislativa. Cuando el enfrentamiento entre los partidos es bajo, es mayor la posibilidad de que haya cooperación para pasar la agenda legislativa. Por el contrario, cuando dos o más de los principales partidos tienen posiciones demasiado encontradas, la contienda en el Congreso inhibirá la construcción de coaliciones parlamentarias para aprobar la agenda legislativa del ejecutivo. Finalmente, el liderazgo del presidente y otros líderes partidistas también son componentes fundamentales que facilitan la aprobación de la agenda legislativa. ${ }^{15}$

\section{Responsabilidades compartidas en el proceso de la política pública}

Además de la propuesta, enmienda y veto de iniciativas de ley, el presidente y el Congreso comparten otras responsabilidades. Entre las más importantes está la del proceso de creación e implementación de políticas y programa públicos. Los legisladores modifican y aprueban las leyes que contienen lineamientos y principios generales que los funcionarios públicos deben seguir durante la implementación de los programas y políticas públicas. Sin embargo, aunque los legisladores intervienen en la etapa del diseño de las políticas al establecer ciertas disposiciones en las leyes y aprobar recursos, los responsables directos de la ejecución no son miembros del Congreso, sino la burocracia dependiente del poder ejecutivo. En otras palabras, al crear las leyes los legisladores delegan autoridad a los funcionarios públicos para que éstos den forma y transformen lo estipulado en la legislación en instrumentos concretos (formatos, reglamentos, manuales, etc.) que puedan ser implementados en la

${ }^{15}$ Véase Shugart y Haggard, op. cit.; Sarah A. Binder, "The Dynamics of Congressional Gridlock”, American Political Science Review, vol. 93, núm. 3, 1999, pp. 519-533; Cf. Fang Yi Chiou y Lawrence S. Rothenberg, "Comparing Legislators and Legislatures: The Dynamics of Legislative Gridlock Reconsidered", Political Analysis, vol. 16, núm. 2, 2008, pp. 197-212; Edwards, Barrett y Peake, op. cit.; Richard Neustadt, Presidential Power and the Modern Presidents, Nueva York, The Free Press, 1990; George C. Edwards, III, The Strategic President, Princeton, Princeton University Press, 2009. 
práctica. Por ejemplo, mientras los legisladores aprueban programas de política social en las leyes estableciendo lineamientos y asignando recursos, la burocracia es la que determina -mediante el establecimiento de reglas de operación y el diseño de procedimientos y sistemas- los criterios y requisitos que los individuos deben cumplir para poder ser beneficiarios de dicha política. ${ }^{16}$

En los estudios de ciencia política se ha investigado la relación entre los políticos y la burocracia utilizando la teoría del principalagente. ${ }^{17}$ De acuerdo a este marco analítico, los legisladores (principales) delegan autoridad y recursos a los burócratas (agentes) para el cumplimiento de mandatos y la obtención de resultados. Dado que el trabajo y sobrevivencia de la burocracia depende de las acciones del Congreso, los legisladores tienen ascendencia sobre los funcionarios públicos. ${ }^{18}$ Asimismo, la teoría del principal-agente asume

${ }^{16}$ Algunos de los factores que determinan el grado de autoridad transferida de los legisladores a los funcionarios públicos son la capacidad de los congresistas para definir el contenido y la sustancia de las políticas públicas y la complejidad e importancia del área de política a regular. Entre más alto sea el nivel de conocimiento, experiencia y pericia del Congreso y más importante sea el tema, menor será el grado de autoridad delegada a los burócratas, pues los legisladores preferirán, ceteris paribus, especificar ellos mismos a detalle las disposiciones de las leyes dejando muy poco por regular a las agencias del ejecutivo. Por el contrario, cuando el área a regular es muy compleja, no es un tema relevante para la opinión pública y existe un nivel bajo de profesionalismo en el legislativo, el nivel de delegación de autoridad tenderá a ser mayor pues los congresistas no tendrán la capacidad ni el interés de controlar cada uno de las estipulaciones en esta materia por lo que dejarán a la burocracia más margen de maniobra en el proceso de implementación. Véase John D. Huber y Charles R. Shipan, Deliberate Discretion?, Nueva York, Cambridge University Press, 2002; William T. Gormley, Jr. y Steven J. Balla, Bureaucracy and Democracy, Thousand Oaks, CQ Press, 2013, tercera edición, pp. 78-81.

${ }^{17}$ La relación entre políticos y burócratas ha sido extensamente analizada para el caso norteamericano y otros países desarrollados. Para revisiones de la bibliografía en este tema, véase Huber y Shipan, op. cit., pp. 17-43; Gary Miller, "The Political Evolution of Principal-Agent Models", Annual Review of Political Science, vol. 8, 2005, pp. 203-225; Charles R. Shipan, "Congress and the Bureaucracy", en Paul J. Quirk y Sarah A. Binder (eds.), The Legislative Branch, Nueva York, Oxford University Press, 2005, pp. 432-458; George A. Krause, "Legislative Delegation of Authority to Bureaucratic Agencies", en Robert F. Durant (ed.), The Oxford Handbook of American Bureaucracy, Nueva York, Oxford University Press, 2010, pp. 521544; y B. Dan Wood, "Agency Theory and the Bureaucracy", en ibid., pp. 181-206. ${ }^{18}$ En el artículo se utilizan indistintamente los términos burócrata y funcio- 
que existe un control de los legisladores sobre la burocracia, por lo que los burócratas deben apegarse a los principios y lineamientos establecidos en la legislación al diseñar todos los procesos, sistemas y reglas de las políticas y programas públicos.

En la interacción entre legisladores y funcionarios públicos, existen al menos tres fuentes de conflicto que afectan las relaciones entre el ejecutivo y el Congreso. Primero, uno de los principales supuestos de la teoría principal-agente es que la relación entre estos actores es asimétrica. Mientras que los congresistas tienen el poder para aprobar legislación y asignar recursos a las agencias gubernamentales, la burocracia cuenta con una estructura administrativa compleja, recursos y personal profesionalizado que le permiten tener mayor información y conocimiento especializado sobre las distintas áreas de política pública. Así, aunque los legisladores tienen el poder legal para crear y modificar los programas públicos, hacer reajustes presupuestales o reducir el margen de maniobra de los funcionarios, la burocracia puede aprovechar la asimetría de información y expertise para esquivar las directrices del Congreso y continuar manteniendo o ampliar sus beneficios. Una segunda fuente de tensión en esta relación es que no necesariamente coinciden los intereses de los legisladores con los de la burocracia. La incompatibilidad de objetivos puede producir fricciones entre los dos poderes. Por ejemplo, al aprobar o modificar leyes, los congresistas pueden buscar beneficiar a ciertos grupos y los funcionarios públicos a otros. La burocracia puede aprovechar sus recursos para orientar los programas públicos a su convenienica o al de ciertos grupos sociales o económicos. Finalmente, otro conflicto en la relación entre el ejecutivo y el legislativo es el control, supervisión y monitoreo que ejercen los miembros del Congreso sobre el trabajo de los funcionarios públicos. Mediante varios mecanismos ex ante $\mathrm{o}$ ex post -tales como el establecimiento de requerimientos y procedimientos a seguir en las leyes, comparecencias, informes, auditorías, ratificaciones, etc.-, el legislativo revisa el trabajo burocrático y en su caso denuncia o sanciona las irregularidades e

nario público para referirse los trabajadores de las agencias gubernamentales pertenecientes al poder ejecutivo. 
incumplimientos cometidos. Por lo tanto, el presidente y el Congreso no sólo comparten responsabilidades, sino que los legisladores tienen el mandato de vigilar, controlar y en su caso sancionar las acciones de las agencias dependientes del ejecutivo. El hecho de que el legislativo tenga el mandato y la autoridad para vigilar y sancionar a las agencias públicas provoca una fricción constante en la relación entre los dos poderes.

Por ejemplo, el nivel de conflicto entre las dos instituciones se eleva cuando alguna política o programa público no está logrando los resultados esperados por los legisladores ${ }^{19}$ o cuando los medios o alguna organización de la sociedad civil denuncia alguna irregularidad. Al hacerse públicos los incumplimientos o las malas prácticas de las agencias gubernamentales, los legisladores responsabilizan a los funcionarios (incluido el presidente) por la falta de resultados o por haber interpretado las leyes en su beneficio o el de algún grupo de interés. Por su parte, los burócratas frecuentemente argumentan que la normatividad tiene demasiados constreñimientos, deficiencias, contradicciones o huecos legales que impiden su correcta implementación. Por el contrario, cuando un programa gubernamental produce resultados eficientes, legisladores y funcionarios públicos intentan acreditarse los logros.

En suma, la división de poderes del sistema presidencial dificulta la relación entre el ejecutivo y legislativo, pues son "instituciones separadas que compiten por porciones poder". ${ }^{20} \mathrm{La}$ separación de poder inherente en esta forma de gobierno abre la posibilidad a que inevitablemente existan varias fuentes de tensiones y problemas entre los poderes ejecutivo y legislativo. ${ }^{21}$ Estas

${ }^{19}$ A este hecho se le conoce como pérdida de agencia (agency loss). Ocurre cuando el agente es incapaz de cumplir con los objetivos estipulados por el principal. Gormley, Jr. y Balla, op. cit., p. 75.

${ }^{20}$ Jones, op. cit., p. 207.

${ }^{21}$ Otra fuente de conflicto entre el ejecutivo y el legislativo que ocurre en los sistemas presidenciales son las ambigüedades o huecos legales en la Constitución y otras normas. La falta de claridad en la Constitución, por ejemplo, da pie a que un poder reclame -mediante algún instrumento legal- ante la Suprema Corte o Tribunal de Justicia que el otro poder está usurpando ciertas funciones que sólo le competen a una institución. 
fricciones frecuentemente tienen efectos en la legislación y las políticas públicas que se derivan. Algunas veces mejoran el contenido de las leyes, pues el Congreso enmienda las propuestas del ejecutivo para hacer programa públicos más eficientes e inclusivos, mientras que en otras ocasiones las enmiendas de los legisladores complican la implementación de los políticas públicas pues se añaden requerimientos, procesos y objetivos en las leyes que la burocracia encuentra difícil de cumplir.

La siguiente sección analiza dos aspectos clave de la relación ejecutivo-legislativo en el sexenio del presidente Felipe Calderón: la tasa de aprobación presidencial y las observaciones del ejecutivo a los decretos aprobados por el Congreso de la Unión. Asimismo se evalúa hasta qué punto el sistema presidencial multipartidista con separación de propósito tuvo un efecto en la producción legislativa en el periodo analizado.

\section{LA APROBACIÓN DE LA AGENDA LEGISLATIVA DEL PRESIDENTE Felipe Calderón}

Después de haber obtenido la victoria electoral por una mínima diferencia en los disputados comicios presidenciales de 2006, el presidente Felipe Calderón inició su administración con un gobierno sin mayoría. ${ }^{22}$ Como puede observarse en las tablas 1 y 2 , al iniciar la LX Legislatura (2006-2009) el Partido Acción Nacional obtuvo 41.4 y $40.6 \%$ de las curules en la Cámara de Diputados y Senadores

${ }^{22}$ A los gobiernos sin mayoría se les conoce en México como gobiernos divididos. Sin embargo, en la historia política reciente del país no ha habido gobiernos divididos sino gobiernos sin mayoría, pues ningún partido político ha obtenido el 50\% más 1 de los escaños necesarios para aprobar la legislación ordinaria. Los gobiernos divididos se presentan cuando un partido diferente al del presidente cuenta con una mayoría en el Congreso (en el caso de los sistemas bicamerales, un partido de oposición controla al menos una de las dos cámaras). No obstante, los medios y una parte de la bibliografía han catalogado a los gobiernos sin mayoría presentados en México desde 1997 como divididos. Véase Robert Elgie, "What Is Divided Government?”, en Robert Elgie (ed.), Divided Government in Comparative Perspective, Nueva York, Oxford University Press, 2001, pp. 1-20. 
respectivamente. Este contexto político causó una separación de propósito, pues ni el presidente ni ningún partido de oposición tenían la opción de pasar sus agendas sin la anuencia del otro.

\section{TABLA 1}

Composición partidaria de la cámara de diputados por tipo de elección y grupo parlamentario LX Legislatura (2006-2009) ${ }^{\mathrm{a}}$

\begin{tabular}{|c|c|c|c|c|c|c|c|c|}
\hline \multirow{2}{*}{$\begin{array}{c}\text { Grupo } \\
\text { parlamentario }\end{array}$} & \multirow{2}{*}{$\begin{array}{l}\text { Mayoría } \\
\text { relativa }\end{array}$} & \multirow{2}{*}{$\begin{array}{l}\text { Representación } \\
\text { proporcional }\end{array}$} & \multicolumn{5}{|c|}{ Circunscripción } & \multirow[b]{2}{*}{ Total } \\
\hline & & & $1 a$ & $2 a$ & $3 a$ & $4 a$ & $5 a$ & \\
\hline PAN & 137 & 70 & 17 & 19 & 11 & 11 & 12 & $\begin{array}{c}207 \\
(41.4) *\end{array}$ \\
\hline PRD & 90 & 36 & 4 & 4 & 8 & 12 & 8 & $\begin{array}{c}126 \\
(25.2)\end{array}$ \\
\hline PRI & 65 & 42 & 11 & 8 & 11 & 5 & 7 & $\begin{array}{c}107 \\
(21.4)\end{array}$ \\
\hline Convergencia & 6 & 12 & 1 & 1 & 3 & 4 & 3 & $\begin{array}{c}18 \\
(3.6)\end{array}$ \\
\hline PVEM & 0 & 17 & 3 & 4 & 4 & 3 & 3 & $\begin{array}{c}17 \\
(3.4)\end{array}$ \\
\hline PT & 2 & 9 & 2 & 2 & 2 & 1 & 2 & $\begin{array}{c}11 \\
(2.2)\end{array}$ \\
\hline NA & 0 & 9 & 2 & 2 & 1 & 2 & 2 & $\begin{array}{c}9 \\
(1.8)\end{array}$ \\
\hline PSD & 0 & 5 & 0 & 0 & 0 & 2 & 3 & $\begin{array}{c}5 \\
(1)\end{array}$ \\
\hline Total & 300 & 200 & 40 & 40 & 40 & 40 & 40 & $\begin{array}{c}500 \\
(100)\end{array}$ \\
\hline
\end{tabular}

${ }^{a}$ Las tablas 1, 2 y 3 muestran la composición partidaria original de las cámaras. A lo largo de las legislaturas algunos legisladores cambiaron de bancada parlamentaria o se hicieron independientes. El caso más famoso fue el "préstamo" de tres senadores que hizo el Partido de la Revolución Democrática al Partido del Trabajo al inicio de la LX Legislatura para que el último pudiera conformar un grupo parlamentario y así obtener prerrogativas. Véase Andrea Becerril y Georgina Saldierna, "Deja Ricardo Monreal fracción del PRD en el Senado y se integra a la del PT", La Jornada, 12 de diciembre de 2008, http://www.jornada.unam.mx/ 2008/12/12/index.php?section=politica\&article=018n1 pol

* El número en paréntesis indica el porcentaje de asientos del partido con respecto al número total de curules en la cámara.

Fuente: Elaboración propia basado en http://sitl.diputados.gob.mx/cuadro_tipo_elec.php 
TABla 2

Composición partidaria del senado de la república por tipo de elección y grupo parlamentario LX y LXI legislaturas

(2006-2012)

\begin{tabular}{ccccc}
\hline $\begin{array}{c}\text { Grupo } \\
\text { parlamentario }\end{array}$ & $\begin{array}{c}\text { Mayoría } \\
\text { relativa }\end{array}$ & $\begin{array}{c}\text { Primera } \\
\text { minoría }\end{array}$ & $\begin{array}{c}\text { Representación } \\
\text { proporcional }\end{array}$ & Total \\
\hline PAN & 32 & 9 & 11 & 52 \\
PRD & 19 & 4 & 6 & $\begin{array}{c}(40.62)^{*} \\
29 \\
(22.65)\end{array}$ \\
PRI & 8 & 18 & 6 & 32 \\
& & & & $(25)$ \\
Convergencia & 3 & 0 & 2 & 5 \\
PVEM & 2 & 0 & 4 & $(3.9)$ \\
& & & & $(4.68)$ \\
PT & 0 & 0 & 2 & $(1.56)$ \\
& & & & 2 \\
NA & 0 & 32 & 32 & $(1.56)$ \\
Total & 64 & & & $(100)$ \\
\hline
\end{tabular}

* El número en paréntesis indica el porcentaje de asientos del partido con respecto al número total de curules en la cámara.

Fuente: Elaboración propia con base en http://sil.gobernacion.gob.mx/Numeralia/Legisladores/NumeraliaLegisladores.php?SID=

Además de no contar con una mayoría de su partido, el presidente Calderón se enfrentó a un Congreso en donde tres de las fracciones parlamentarias (PRD, PT y Convergencia/MC, equivalentes a $31 \%$ de la Cámara de Diputados y $28 \%$ en el Senado en la LX Legislatura) no reconocieron su triunfo electoral y consecuentemente tampoco su investidura como titular del ejecutivo federal. Desde el inicio del mandato, el enfrentamiento de los partidos de izquierda con el presidente Calderón y su partido tuvo repercusiones en la relación entre el ejecutivo y el legislativo. Para empezar, la toma de posesión el primero de diciembre de 2006 fue muy complicada pues los legisladores de izquierda intentaron impedirla al 
cerrar los accesos al salón del pleno de la Cámara de Diputados. Felipe Calderón tuvo que inmiscuirse por una puerta trasera para llegar a la tribuna del recinto legislativo y rendir protesta como titular del ejecutivo. ${ }^{23}$ Este suceso fue el inicio de una larga animadversión entre los partidos de oposición de izquierda y el presidente. Sin embargo, como se documenta más adelante, la falta de reconocimiento de los partidos de izquierda al ejecutivo se quedó en gran medida en un nivel retórico ya que no tuvo amplios efectos en la tasa de aprobación de la agenda del presidente en el Congreso. ${ }^{24}$

\section{Las legislaturas LX y LXI}

Un aspecto de suma importancia en la relación ejecutivo-legislativo es la tasa de aprobación de la agenda legislativa del presidente en el Congreso de la Unión. Durante la LX Legislatura (2006-2009), Felipe Calderón mandó 67 proyectos de ley al Congreso, 32 a la Cámara Baja y 35 al Senado. En este periodo legislativo, el presidente tuvo una tasa de aprobación de $85 \%$, la cual fue superior al promedio de iniciativas aprobadas al poder ejecutivo durante los gobiernos sin mayoría anteriores (1997-2006). ${ }^{25}$ Es importante señalar que las dos cámaras no rechazaron ninguna de las 67 iniciativas que

${ }^{23}$ Claudia Guerrero, Érika Hernández y Claudia Salazar, "Sesionan en el caos", Reforma, 2 de diciembre de 2006.

${ }^{24}$ Otro dato que sustenta que el enfrentamiento entre el presidente Calderón y los partidos de oposición de izquierda no tuvo mayores efectos en la relación entre los poderes ejecutivo y legislativo es que el partido del presidente, Acción Nacional, formó coaliciones con el Partido de la Revolución Democrática -y también el Revolucionario Institucional- en múltiples ocasiones durante las LX y LXI Legislaturas. Un ejemplo de esto es que durante la LX Legislatura, cuando la tensión entre el presidente y la izquierda estaba en su nivel más alto, la coalición PAN-PRIPRD votó el $83 \%$ de las reformas constitucionales en la Cámara de Diputados. Véase María Amparo Casar e Ignacio Marván, "Pluralismo y reformas constitucionales", en María Amparo Casar e Ignacio Marván (coords.), Reformar sin mayorías, México, Taurus, 2014, p. 41.

${ }^{25}$ La tasa de aprobación durante este periodo en la Cámara de Diputados fue de 77\%. Véase Casar, "Quince años de gobiernos sin mayoría en el Congreso mexicano”, op. cit., p. 236. 
presentó el presidente. ${ }^{26}$ Las diez propuestas o modificaciones de ley del ejecutivo que no fueron aprobadas, en estricto sentido, no fueron rechazadas, pues se quedaron como pendientes en la cámara de origen o en la cámara revisora. La mayoría de estas iniciativas fueron en materia de seguridad pública y justicia. De las 57 iniciativas de ley que sí lograron aprobación en ambas cámaras del Congreso de la Unión, cinco fueron reformas constitucionales y 52 leyes secundarias.

Respecto a la temática del total de iniciativas aprobadas al ejecutivo, poco más de la mitad (55\%) fue en materia hacendaria y financiera. Además de la ley de ingresos, el presupuesto de egresos y la miscelánea fiscal que cada año son presentadas por el ejecutivo y aprobadas por la Cámara de Diputados, el presidente Calderón introdujo al Congreso diversas iniciativas que crearon varios impuestos, tales como el impuesto contra la informalidad y el impuesto empresarial a tasa única. Asimismo, se modificó la legislación fiscal para establecer un incremento del uno por ciento al impuesto sobre la renta y ajustar el impuesto especial sobre producción y servicios.

La segunda área donde se concentraron más iniciativas del ejecutivo fue la de seguridad y justicia, las cuales fueron parte de su estrategia para combatir al crimen organizado. ${ }^{27}$ Entre las modificaciones relevantes que se hicieron en este ámbito están: la que permite a las autoridades federales conocer los delitos del fuero

${ }^{26}$ No obstante, es importante considerar la anticipación que hace el ejecutivo sobre la probabilidad de éxito de las iniciativas que envía al Congreso de la Unión. Cuando el presidente prevé que hay pocas expectativas de que su propuesta sea aceptada tenderá a abstenerse de enviarla o la modificará sustancialmente para así incrementar la probabilidad de aceptación. Sobre la teoría de anticipaciones del ejecutivo véase Cohen, op. cit.

${ }^{27}$ La tercera área temática en la que el presidente Calderón propuso más reformas fue la de administración y organización del gobierno y en cuarto lugar destacan seis propuestas relacionadas al sector energético entre las cuales destaca las modificaciones al régimen fiscal de PEMEx para establecer el pago de un derecho diferenciado en la explotación de petróleo crudo y gas natural. Véase la "Iniciativa de decreto que reforma y adiciona diversas disposiciones de la Ley Federal de Derechos". Gaceta Parlamentaria, 14 de mayo de 2008, http://www.gaceta.diputados.gob.mx 
común, la que faculta al Congreso a legislar en materia de secuestro y elevar las penas por este delito, el fortalecimiento y ampliación de las facultades de la policía, el establecimiento de sanciones para los militares que se incorporen al crimen organizado, la desaparición de la Policía Federal Preventiva y la creación de la Policía Federal, la instauración del servicio profesional de carrera para los agentes del ministerio público, la Ley Federal contra la Delincuencia Organizada y el Código Penal Federal, ${ }^{28}$ la permisión de la extinción de dominio, la aprobación de la Ley General del Sistema Nacional de Seguridad Pública y diversas modificaciones al Código Federal de Procedimientos Penales. ${ }^{29}$

Entre las iniciativas más importantes del ejecutivo que se quedaron pendientes en el Congreso de la Unión están la que proponía la aportación de seguridad social para atender enfermedades producto del tabaquismo, modificaciones legales en relación a la posesión y uso de armas de fuego y explosivos por parte de la ciudadanía, la propuesta que tipificaba como grave el delito de extorsión, la que proponía elevar las penas al delito de violencia familiar, reformas a la Ley de Seguridad Nacional que permitían la participación de las fuerzas armadas en situaciones que afecten la seguridad interior, la iniciativa de fortalecimiento a la banca de desarrollo y la que proponía la autonomía de la Procuraduría General de la República.

Para la LXI Legislatura (2006-2009), el apoyo legislativo del presidente Calderón disminuyó, pues las elecciones intermedias produjeron una pérdida de 65 asientos para el PAN en la cámara baja, con que quedó con $28.4 \%$ de los asientos. Este resultado electoral hizo que el partido del presidente dejara de ser la primera mayoría en este recinto cediendo esta posición al PRI (tabla 3). ${ }^{30}$

${ }^{28}$ Estas reformas permitieron establecer el registro nacional de detención, incluir las grabaciones particulares como elementos probatorios, crear la figura de denuncia anónima y la reserva de identidad para agentes infiltrados, construir centros de máxima seguridad, entre otros aspectos.

${ }^{29}$ Esta norma estableció la certificación de cuerpos policiacos en los Centros de Evaluación y Control de Confianza de las Instituciones de Seguridad Pública entre otros aspectos en materia de seguridad pública.

${ }^{30}$ De hecho, como puede observarse en la tabla 3, al PRI sólo le faltaron 9 
TABla 3

Composición partidaria de la cámara de diputados por tipo de elección y grupo parlamentario LXI Legislatura (2009-2012)

\begin{tabular}{|c|c|c|c|c|c|c|c|c|}
\hline \multirow{2}{*}{$\begin{array}{c}\text { Grupo } \\
\text { parlamentario }\end{array}$} & \multirow{2}{*}{$\begin{array}{l}\text { Mayoría } \\
\text { relativa }\end{array}$} & \multirow{2}{*}{$\begin{array}{l}\text { Representación } \\
\text { proporcional }\end{array}$} & \multicolumn{5}{|c|}{ Circunscripción } & \multirow[b]{2}{*}{ Total } \\
\hline & & & $1 a$ & $2 a$ & $3 a$ & $4 a$ & $5 a$ & \\
\hline PAN & 68 & 74 & 18 & 18 & 16 & 11 & 11 & $\begin{array}{c}142 \\
(28.4) *\end{array}$ \\
\hline PRD & 35 & 30 & 3 & 3 & 7 & 8 & 9 & $\begin{array}{c}65 \\
(13)\end{array}$ \\
\hline PRI & 188 & 54 & 11 & 12 & 12 & 8 & 11 & $\begin{array}{c}242 \\
(48.4)\end{array}$ \\
\hline MC & 0 & 6 & 0 & 0 & 2 & 2 & 2 & $\begin{array}{c}6 \\
(1.2)\end{array}$ \\
\hline PVEM & 4 & 18 & 4 & 4 & 2 & 5 & 3 & $\begin{array}{c}22 \\
(4.4)\end{array}$ \\
\hline PT & 4 & 10 & 2 & 1 & 1 & 4 & 2 & $\begin{array}{c}14 \\
(2.8)\end{array}$ \\
\hline NA & 1 & 8 & 2 & 2 & 0 & 2 & 2 & $\begin{array}{c}9 \\
(1.8)\end{array}$ \\
\hline Total & 300 & 200 & 40 & 40 & 40 & 40 & 40 & $\begin{array}{c}500 \\
(100)\end{array}$ \\
\hline
\end{tabular}

* El número en paréntesis indica el porcentaje de asientos del partido con respecto al número total de curules en la cámara

Fuente: Elaboración propia con base en http://sitl.diputados.gob.mx/LXI_ leg/cuadro_tipo_elec.php

En esta legislatura el presidente Calderón mandó 55 proyectos de ley al poder legislativo: ${ }^{31} 30$ a la Cámara de Diputados, 18 al

diputados para conseguir la mayoría absoluta en esta cámara, lo que era fácilmente alcanzable con sus aliados del Partido Verde Ecologista de México.

${ }^{31}$ Es importante precisar que el número de iniciativas sustantivas del ejecutivo en este periodo fue menor, pues siete de las 55 iniciativas presentadas fueron de carácter administrativo y de gobierno interior. Estas iniciativas generalmente versan sobre asuntos de poca relevancia como el establecimiento de características a monedas conmemorativas, por lo que generalmente no hay mayor discusión ni debate sobre éstas en el Congreso. No obstante, en esta legislatura una de estas iniciativas fue rechazada por la cámara revisora y quedó pendiente en la cámara de origen. Véase "Iniciativa que establece las características de la novena moneda 
Senado y siete a la Comisión Permanente. ${ }^{32}$ Respecto al tipo de iniciativas presentadas, el ejecutivo sólo mandó dos reformas constitucionales, cinco de carácter administrativo y de gobierno y 48 iniciativas a leyes secundarias. La tasa de aprobación legislativa del ejecutivo sufrió una caída respecto al periodo anterior, pues perdió casi 16 puntos, y quedó en $69.1 \%$. A diferencia de la legislatura anterior en la cual no se rechazó ninguna iniciativa del presidente, los legisladores en este periodo no dieron su aval para dos iniciativas del ejecutivo además de dejar más reformas pendientes para un total de quince. ${ }^{33}$ Las áreas de política pública de las iniciativas presentadas por el presidente Calderón durante la LXI Legislatura se mantuvieron, aunque en proporciones distintas. Al igual que en el periodo anterior, las iniciativas del ejecutivo en materia hacendaria y financiera fueron las más numerosas. No obstante, en esta legislatura predominaron las propuestas de ley de carácter administrativo y de organización interior sobre las de seguridad y justicia quedando al último las modificaciones en el sector energético. ${ }^{34}$

Entre las iniciativas del ejecutivo más importantes aprobadas durante esta legislatura hay diversas modificaciones a la Ley Federal de Derechos, incluido un cambio al régimen fiscal de Petróleos Mexicanos. También en materia fiscal se modificó el impuesto especial de producción y servicios. Este cambio incrementó los impuestos a cierto tipo de bebidas alcohólicas, tabaco, juegos con

de plata conmemorativa del Quinto Centenario del Encuentro de Dos Mundos", Gaceta Parlamentaria, 24 de abril de 2012.

${ }^{32}$ La comisión permanente turnó cinco de estas iniciativas al Senado y dos a la Cámara de Diputados.

${ }^{33}$ La iniciativa de reforma a la Ley General de Salud que quedó pendiente en la LXI Legislatura fue aprobada en el siguiente periodo legislativo. Véase "Iniciativa que reforma las fracciones I y III del artículo 245 de la Ley General de Salud”, Gaceta Parlamentaria, 25 de enero de 2012.

${ }^{34}$ Dos iniciativas de ley no pudieron ser clasificadas en alguna de las categorías mencionadas. La primera ofrece garantías a las personas refugiadas mientras que la segunda propone modificar la clasificación a las sustancias psicotrópicas. Véase Iniciativa que expide la Ley sobre Refugiados y Protección Complementaria, y que reforma, adiciona y deroga diversas disposiciones de la Ley General de Población e Iniciativa que reforma las fracciones I y III del artículo 245 de la Ley General de Salud, Gaceta Parlamentaria,12 de mayo de 2010 y 25 de enero de 2012. 
apuestas y sorteos y servicios de telecomunicaciones. En términos de política social, a propuesta del ejecutivo se hicieron cambios a la Ley General de Salud para cambiar el esquema de transferencias federales a los estados por el concepto del Seguro Popular. ${ }^{35}$ Para fomentar la inversión pública y privada e incentivar la infraestructura en el país el Congreso de la Unión aprobó la Ley de Asociaciones Público Privadas propuesta por el presidente Calderón.

\section{GRÁFICA}

Iniciativas propuestas por el presidente Calderón por área de política pública LX y LXI Legislaturas

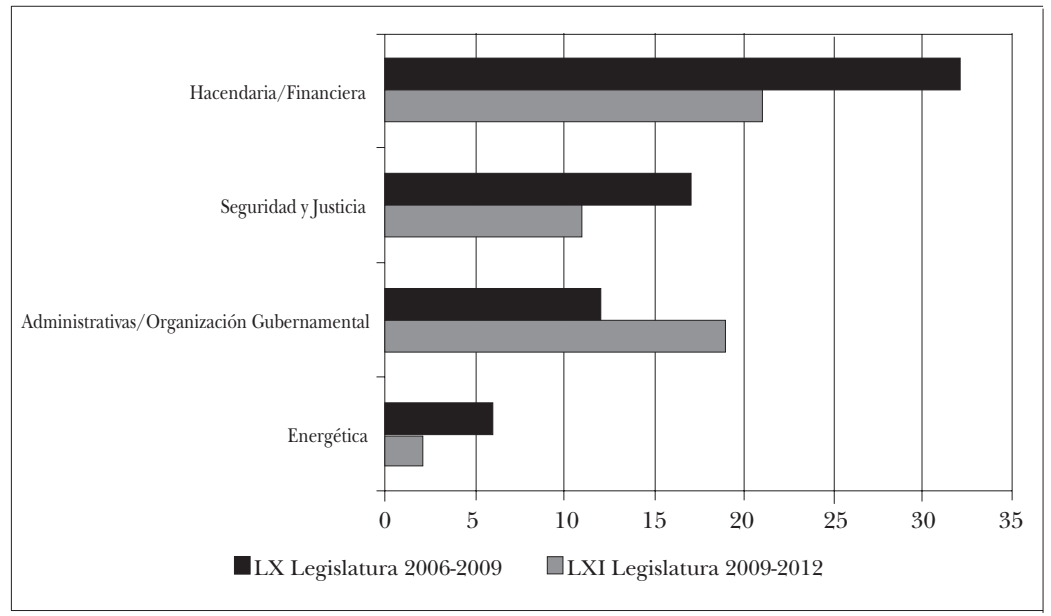

Por otra parte, en diciembre de 2009 el ejecutivo introdujo una iniciativa que pretendía transformar a fondo diversos aspectos del sistema político. Aunque el poder legislativo no dio su aval para permitir la reelección legislativa ni la segunda vuelta presidencial,

${ }^{35}$ Esta modificación eliminó los padrones de familias beneficiadas como base para determinar las transferencias federales. El nuevo esquema considera el número de personas afiliadas al Seguro Popular como base. Véase Iniciativa que reforman los artículos 77 bis 12 y 77 bis 13 de la Ley General de Salud. Diario Oficial de la Federación, 30 de diciembre de 2009. 
sí aprobaron las candidaturas independientes, la consulta popular, las iniciativas preferentes y ciudadana, el procedimiento para la designación del presidente en caso de falta absoluta, entre otras disposiciones. En materia de seguridad pública, el ejecutivo presentó en febrero de 2010 la Ley General para Prevenir y Sancionar los Delitos en Materia de Secuestro. Este ordenamiento fue acompañado por diversas modificaciones a otras leyes en materia de seguridad y justicia que permitieron, entre otros aspectos, la intervención de las autoridades a las comunicaciones privadas, operaciones encubiertas y la protección integral a víctimas. Asimismo se expidió la Ley Federal para la Prevención e Identificación de Operaciones con Recursos de Procedencia Ilícita y de Financiamiento al Terrorismo, la cual limitó, entre otros rubros, las operaciones mediante pago de moneda, billetes o metales preciosos con un tope máximo de 100000 pesos. Para combatir la corrupción, el presidente Calderón propuso la iniciativa para crear la Ley Federal Anticorrupción en Contrataciones Públicas. Durante la LXI Legislatura el Congreso de la Unión le aprobó al ejecutivo federal cambios a la Ley Federal de Competencia que reestructuraron internamente a la extinta Comisión Federal de Competencia además de otorgarle facultades adicionales.

Las dos iniciativas del ejecutivo rechazadas durante este periodo fueron la que impulsaba la modernización al sistema de impartición de justicia mediante la utilización de medios digitales como el correo y la firma electrónica, y la propuesta que reorganizaba la administración pública federal. Entre los cambios propuestos en esta última iniciativa estaban la desaparición de las secretarías de Turismo, Función Pública y Reforma Agraria. Por su parte, entre las propuestas más relevantes del presidente Calderón que quedaron pendientes, están la ley que establecía la contribución para el combate a la pobreza, la Ley del Sistema de Seguridad Pública del Distrito Federal, la iniciativa que proponía el mando único policial en las entidades federativas, y modificaciones a diversos ordenamientos penales y otras leyes para mermar la estructura financiera de las organizaciones criminales mediante acciones como el decomiso de los bienes del inculpado. También quedó pendiente de dictamen la iniciativa que proponía hacer anónimo el sistema de denuncias en 
las dependencias de la administración pública y la propuesta que expedía un código federal de procedimientos penales.

Durante los últimos tres meses de su mandato, en la LXII Legislatura (2012-2015), el presidente Calderón mandó diez iniciativas de ley al Congreso de la Unión (dos a la Cámara de Diputados y ocho al Senado de la República). Ambas cámaras dieron el aval a cuatro propuestas entre las que sobresalen las dos iniciativas preferentes utilizadas por el presidente Calderón para modificar la Ley Federal del Trabajo y la Ley General de Contabilidad Gubernamental. Entre los cambios incluidos a la legislación laboral está la autorización para nuevas modalidades de contratación como el outsourcing, el establecimiento de nuevos mecanismos para la rescisión de contratos, límites a la generación de salarios vencidos, el pago por hora y algunos avances en materia de transparencia y rendición de cuentas sindical. La segunda iniciativa preferente utilizada permitió la homogeneización de la información financiera de los tres órdenes de gobierno estableciendo normas y formatos estándar, además de diversas modificaciones encaminadas a transparentar y hacer más accesible la utilización de los recursos públicos a la opinión pública. ${ }^{36}$ Ninguna de las seis iniciativas restantes mandadas por el presidente Calderón durante este periodo fue rechazada. Sin embargo, al menos la iniciativa que proponía la Ley General de Atención y Protección de Víctimas puede considerarse como descartada. Aunque esta iniciativa no ha sido oficialmente desechada por el Senado, el cual fungió como cámara de origen, y en principio continúa como una propuesta pendiente de dictaminar, es un hecho que no será aprobada, pues el 9 de enero de 2013 fue promulgada otra ley que regula la misma temática: la Ley General de Víctimas. ${ }^{37}$

${ }^{36}$ Las otras dos iniciativas del ejecutivo aprobadas durante estos meses de las LXII Legislatura fueron la Ley de Vertimientos de las Zonas Marinas Mexicanas, la cual está orientada a controlar y prevenir la contaminación del mar y la nueva Ley de Instituciones de Seguros y de Fianzas.

${ }^{37}$ La Ley General de Víctimas fue aprobada por el Congreso de la Unión el 30 abril de 2012, pero el ejecutivo la devolvió con observaciones dos meses después. Los legisladores argumentaron que dichas observaciones fueron hechas fuera del plazo establecido por la Constitución. Ante la diferencia, el 19 de julio el 
Otra iniciativa del presidente Calderón que muy difícilmente será aprobada durante la presente y siguiente legislatura es la que proponía la segunda vuelta electoral. Aunque este tema fue parte de la discusión política durante las negociaciones del Pacto por México, los tres partidos principales decidieron dejar este tema fuera de los cambios constitucionales en materia de reforma política aprobados en 2013. ${ }^{38}$ También quedaron pendientes por dictaminar las modificaciones a la Ley agraria para fortalecer los derechos de los ejidatarios sobre el uso de su parcela y la Ley de Refugiados y Protección Complementaria, la cual pretendía definir con claridad los conceptos de refugiado y asilado además de regular el procedimiento de otorgamiento de ambas figuras. ${ }^{39}$

En suma, se puede argumentar que cuantitativamente el presidente Calderón tuvo éxito en pasar su agenda legislativa, pues casi $77 \%$ de sus iniciativas durante su gestión fueron aprobadas. En otras palabras, un poco más de tres de cada cuatro de sus propuestas fueron avaladas por los legisladores a pesar de que no contó con una mayoría partidaria que los respaldara durante su mandato. Asimismo, cabe resaltar que el presidente Calderón obtuvo un porcentaje de aprobación de su agenda ligeramente mayor al de su predecesor Vicente Fox (74.7\%), lo que no deja de sorprender dado que los partidos de izquierda nunca lo reconocieron públicamente como

\footnotetext{
presidente Calderón decidió presentar una controversia constitucional ante la Suprema Corte de Justicia para que dirimiera si las observaciones realizadas a ley cumplieron con lo establecido en la carta magna. Adicionalmente, el ejecutivo presentó una nueva iniciativa de ley -la Ley General de Atención y Protección de Víctimas- que pretendía reemplazar y enmendar las supuestas omisiones y contradicciones de la Ley General de Víctimas. La controversia sobre si las observaciones a la Ley General de Víctimas fueron constitucionales fue aceptada, pero antes de que la Suprema Corte emitiera una sentencia, el presidente entrante, Enrique Peña Nieto, se desistió de dicha controversia. Al no haber impedimento legal, la Ley General de Víctimas fue promulgada los primeros días de 2013 tal y como fue aprobada por el Congreso de la Unión en abril de 2012.

38 Véase Claudia Guerrero, "Jalan reforma política Gobierno y Senado", Reforma, 17 de octubre de 2013, p. 11.

${ }^{39}$ Esta última iniciativa es la que más probabilidad tiene de ser promulgada, pues en abril de 2013 el Senado de la República la aprobó. Actualmente está pendiente de dictaminación en la Cámara de Diputados.
} 
un interlocutor válido. No obstante, una valoración cualitativa de la aprobación de la agenda presidencial durante este periodo arroja un resultado mucho más moderado en cuanto a la efectividad del presidente, dado que varias de sus iniciativas clave en diferentes aspectos no se aprobaron, fueron desechadas o se modificaron sustancialmente.

Por ejemplo, en el rubro hacendario y financiero, el presidente Calderón no contó con el apoyo para crear un impuesto al consumo destinado al combate a la pobreza, permitir a las entidades que implementaran un impuesto local a la gasolina y diesel ni modificar varios ordenamientos financieros para fortalecer la banca de desarrollo y promover así la inversión y la generación de empleos, los cuales fueron dos de las principales promesas de campaña. En el tema de procuración de justicia y seguridad, aunque el ejecutivo pudo concretar varios cambios de trascendencia, algunas otras propuestas muy relevantes para transformar esta área de política pública -como el mando único policial, la creación de un nuevo código federal de procedimientos penales y el otorgamiento de autonomía a la Procuraduría General de la República- no convencieron al poder legislativo. En cuanto a la reorganización de la estructura de la administración pública federal, las propuestas del ejecutivo encaminadas a fortalecer a algunas dependencias (otorgándoles más atribuciones) y a adelgazar el aparato burocrático (desapareciendo tres secretarías) fueron rechazadas cabalmente por los legisladores.

Finalmente, aunque hubo algunas modificaciones en el sector energético, el presidente Calderón no fue capaz de que el Congreso aprobara los puntos nodales de su reforma energética presentada en abril del 2008. El conjunto de iniciativas para transformar la industria petrolera fue sustancialmente modificado por los partidos de oposición, por lo que los cambios a la normatividad correspondiente aprobados por el legislativo quedaron muy distantes de la propuesta original mandada por el presidente Calderón. ${ }^{40}$

${ }^{40}$ La reforma energética del presidente Calderón planteaba, entre otros puntos, la participación de la iniciativa privada en las actividades de refinación del petróleo y contratos de desempeño. Los partidos de oposición rechazaron esta 


\section{El veto presidencial}

Como se analizó en la sección anterior, la aprobación de la agenda del presidente por el Congreso refleja en buena medida el estado de la relación entre los poderes ejecutivo-legislativo en un sistema presidencial. De igual importancia para la interacción entre los poderes son las observaciones o vetos que hace el presidente a las leyes y modificaciones aprobados por el Congreso. En principio, si el titular del poder ejecutivo utiliza con mucha frecuencia este instrumento para mantener el statu quo y cuenta con los asientos suficientes para sostenerlo, la relación con los legisladores de oposición puede afectarse y producirse una parálisis legislativa, pues los miembros del Congreso tenderán a no aprobar las iniciativas del presidente. Asimismo, si el ejecutivo veta constantemente los decretos aprobados por los legisladores y el Congreso supera sus observaciones, la imagen del presidente puede verse dañada mientras pierde credibilidad con sus interlocutores y con la ciudadanía en general. ${ }^{41}$

Durante su mandato, el presidente Calderón observó nueve decretos de ley. ${ }^{42}$ Como se indica en la tabla 4 , dos terceras partes de las observaciones fueron hechas durante el segundo trienio de la administración. ${ }^{43} \mathrm{Al}$ igual que su predecesor, el presidente Calderón

propuesta. Véase Claudia Guerrero y Érika Hernández, “Avalan en el Senado nueva era de Pemex", Reforma, 24 de octubre de 2008.

${ }^{41}$ Las observaciones del ejecutivo a decretos aprobados por el poder legislativo no necesariamente son interpuestas con la finalidad de mantener el statu quo. En algunas ocasiones, el presidente puede estar de acuerdo con los principios y objetivos de la legislación aprobada, pero observa ciertas leyes con la finalidad de corregir y precisar algunas disposiciones o llenar ciertas lagunas legales que podrían contravenir otras normas.

42 Vicente Fox realizó 16 observaciones a decretos durante su periodo como presidente. Siete de los vetos fueron interpuestos durante el antepenúltimo mes de su gestión (septiembre de 2006) ya comenzada la LX Legislatura (2006-2009). Véase los decretos observados por el ejecutivo en el portal del Sistema de información legislativa de la Secretaría de Gobernación: http://www.sil.gob.mx

43 Como se explicó anteriormente, el presidente Calderón intentó vetar la Ley General de Víctimas el primero de julio de 2013. La constitucionalidad de las observaciones aún se encontraba en discusión en la Corte cuando el presidente 
fue capaz de mantener todas sus observaciones ante el Congreso. De hecho, ninguno de sus vetos fue llevado a votación en el pleno de alguna de las cámaras del Congreso para determinar si los legisladores lo superaban. ${ }^{44}$ Por el contrario, lejos de hacer frente al veto presidencial en al menos $55 \%$ de las veces, los legisladores reconocieron explícitamente las inconsistencias o problemas en los decretos aprobados aceptando los puntos observados por el presidente.

Los motivos y razones por los que el ejecutivo interpuso las observaciones a decretos de ley fueron variados, y no únicamente por cuestiones ideológicas o partidistas pues dos de los nueve vetos interpuestos fueron a decretos originalmente presentados por legisladores de su propio partido. Como se mencionó anteriormente, cinco de las nueve observaciones fueron aceptadas por el poder legislativo. Esta aceptación implicó que los legisladores presentaran nuevos dictámenes -los cuales incluyeron las adiciones y modificaciones observadas por el presidente- y fueran aprobados rápidamente por ambas cámaras para finalmente convertirse en leyes. En cuanto al resto de las observaciones, dos fueron desechadas por acuerdo de la cámara de origen meses después de haberse recibido, mientras que las otras dos aún se encuentran en comisiones en espera de dictaminación según lo reporta el sistema de información legislativa de la Secretaría de Gobernación.

Son inciertas las razones del desistimiento del Congreso por superar los vetos interpuestos por el ejecutivo, sobre todo los que no tuvieron respuesta formal del legislativo (las desechadas tiempo después de haberse recibido y las que están pendientes en comisión). Entre las posibles explicaciones está la falta de sustento legal de las leyes aprobadas como es el decreto que pretendía crear un fondo especial de diez mil millones de pesos para atender los daños ocasionados por fenómenos naturales en diversas entidades de la federación. En este caso el presidente Calderón argumentó que el veto se debió a que el decreto violaba la Constitución y la

Peña se desistió de dicho instrumento. Véase la cronología del caso en "Firman Ley de Víctimas", Reforma, 9 de enero de 2013.

${ }^{44} \mathrm{El}$ inciso c del artículo 72 de la Constitución establece que son necesarios dos terceras partes del número total de votos en cada cámara del Congreso de la Unión para revocar el veto. 
Ley Reglamentaria en Materia Presupuestaria, entre otras disposiciones, por no establecer con claridad cuál era fuente de ingresos fiscales para el fondo propuesto. Al parecer, los diputados aceptaron este vacío legal en el presupuesto y ni siquiera turnaron el veto a las comisiones correspondientes para ser estudiado. ${ }^{45}$

Otra posible explicación del desistimiento legislativo para superar los vetos presidenciales es la dificultad para articular una coalición que reúna las dos terceras partes del número total de votos en cada cámara. Cumplir con este requisito constitucional es aún más complicado en un contexto como el mexicano, que desde 1997 ha contado con gobiernos sin mayoría y alta disciplina partidista. De hecho, únicamente considerando la composición partidaria del Senado de la República, al presidente Calderón le bastaba con mantener la cohesión partidaria de su partido para sostener el veto a cualquier decreto, pues el Partido Acción Nacional tuvo $40.6 \%$ de los asientos en esta cámara durante toda su gestión. ${ }^{46}$ No obstante, el bajo número de vetos emitidos durante la LX y LXI Legislaturas sugiere que el ejecutivo federal no tomó ventaja de la fragmentación política y del porcentaje de los senadores de su partido para mantener el statu quo. ${ }^{47}$

En suma, el número bajo de vetos presidenciales, la aceptación explícita por parte de los legisladores a más de las mitad de las observaciones y el desistimiento del Congreso para superar una parte de los vetos, indican que este instrumento no fue una fuente de conflicto y tensión entre el ejecutivo y legislativo durante el periodo analizado.

45 Véase la observación del ejecutivo federal en relación al decreto mediante el cual éste integrará por la SHCP un fondo especial de diez mil millones de pesos para atender los daños ocasionados por las contingencias climáticas en Sonora, Baja California, Baja California Sur, Aguascalientes, Tamaulipas, Coahuila, Chihuahua, Sinaloa, Durango, Nuevo León, Zacatecas, San Luis Potosí, Querétaro, Guanajuato, Tlaxcala, Puebla, México, Hidalgo, Tabasco y Veracruz. Sistema de Información Legislativa, 4 de abril de 2012.

${ }^{46}$ En la LX Legislatura (2006-2009), el partido del presidente obtuvo 41.4\% de los asientos en la Cámara de Diputados por lo que también tuvo condiciones para mantener el veto. Este porcentaje puede explicar por qué el presidente Fox pudo mantener las observaciones presentadas en septiembre de 2006.

${ }^{47}$ En la LX y LXI Legislaturas el Congreso de la Unión aprobó 510 decretos de ley. El presidente Calderón sólo presentó observaciones en 1.7\% de éstos. 
TABla 4

Observaciones del presidente Calderón a decretos emitidos por el Congreso de la Unión 2006-2012

\begin{tabular}{|c|c|c|c|c|}
\hline Legislatura & $\begin{array}{l}\text { Fecha de la } \\
\text { observación }\end{array}$ & $\begin{array}{c}\text { Decreto } \\
\text { observado }\end{array}$ & $\begin{array}{c}\text { Iniciativa originalmente } \\
\text { presentada por }\end{array}$ & Estatus \\
\hline LX & $3 / 09 / 2007$ & $\begin{array}{l}\text { Diversas disposiciones en la } \\
\text { Ley Federal de Protección } \\
\text { al Consumidor }\end{array}$ & $\begin{array}{l}\text { Dip. Francisco Arroyo } \\
\text { Vieyra } \\
\text { (PRI) } \\
14 / 05 / 2005\end{array}$ & $\begin{array}{l}\text { Observaciones } \\
\text { aprobadas } \\
29 / 01 / 2009\end{array}$ \\
\hline LX & $3 / 09 / 2007$ & $\begin{array}{l}\text { Ley de Promoción } \\
\text { y Desarrollo de los } \\
\text { Bioenergéticos }\end{array}$ & $\begin{array}{l}\text { Dip. Cruz López Aguilar } \\
\text { (PRI) } \\
8 / 12 / 2005\end{array}$ & $\begin{array}{l}\text { Observaciones } \\
\text { aprobadas } \\
01 / 02 / 2008\end{array}$ \\
\hline LX & $26 / 03 / 2009$ & $\begin{array}{l}\text { Diversas disposiciones a } \\
\text { la Ley Federal de Radio y } \\
\text { Televisión }\end{array}$ & $\begin{array}{l}\text { Sen. Ricardo García } \\
\text { Cervantes } \\
(\text { PAN) } \\
25 / 05 / 2008\end{array}$ & $\begin{array}{l}\text { Observaciones } \\
\text { aprobadas } \\
19 / 06 / 2009\end{array}$ \\
\hline LXI & $2 / 09 / 2010$ & $\begin{array}{l}\text { Ley General de } \\
\text { Cooperación Internacional } \\
\text { para el Desarrollo }\end{array}$ & $\begin{array}{l}\text { Sen. Rosario Green } \\
\text { Macías } \\
(\text { PRI) } \\
8 / 03 / 2007\end{array}$ & $\begin{array}{l}\text { Observaciones } \\
\text { aprobadas } \\
06 / 04 / 2011\end{array}$ \\
\hline LXI & $9 / 11 / 2010$ & $\begin{array}{l}\text { Diversas disposiciones a la } \\
\text { Ley General de Sociedades } \\
\text { Mercantiles }\end{array}$ & $\begin{array}{l}\text { Dip. José Gildardo } \\
\text { Guerrero Torres } \\
\text { (PAN) } \\
\text { 14/12/2006 }\end{array}$ & $\begin{array}{l}\text { Sin turno a } \\
\text { comisiones } \\
\text { Observación } \\
\text { desechada } \\
\text { 30/04/2013 }\end{array}$ \\
\hline LXI & $29 / 03 / 2011$ & $\begin{array}{l}\text { Art. } 16 \text { Párrafo tercero de la } \\
\text { Ley de Desarrollo } \\
\text { Sustentable }\end{array}$ & $\begin{array}{l}\text { Sen. Antonio Mejía Haro } \\
\text { (PRD) } \\
\text { 18/09/2007 }\end{array}$ & $\begin{array}{l}\text { Pendiente } \\
\text { en comisión } \\
\text { de Cámara } \\
\text { de origen }\end{array}$ \\
\hline LXI & $3 / 11 / 2011$ & $\begin{array}{l}\text { Derechos de los usuarios } \\
\text { de compañía Mexicana de } \\
\text { Aviación y sus filiales }\end{array}$ & $\begin{array}{l}\text { Sen. Tomás Torres } \\
\text { Mercado } \\
\text { (PVEM) } \\
02 / 09 / 2010\end{array}$ & $\begin{array}{l}\text { 29/03/2011 } \\
\text { Pendiente en } \\
\text { comisión de } \\
\text { Cámara de } \\
\text { origen } \\
03 / 11 / 2011\end{array}$ \\
\hline
\end{tabular}


Tabla 4 (conclusión)

\begin{tabular}{|c|c|c|c|c|}
\hline Legislatura & $\begin{array}{l}\text { Fecha de la } \\
\text { observación }\end{array}$ & $\begin{array}{c}\text { Decreto } \\
\text { Observado }\end{array}$ & $\begin{array}{c}\text { Iniciativa originalmente } \\
\text { presentada por }\end{array}$ & Estatus \\
\hline LXI & 4/1/2012 & $\begin{array}{l}\text { Decreto mediante el cual } \\
\text { éste integrará por la SHCP } \\
\text { un fondo especial de } \\
\text { diez mil millones de } \\
\text { pesos para atender los } \\
\text { daños ocasionados por las } \\
\text { contingencias climáticas } \\
\text { en varias entidades de la } \\
\text { República }\end{array}$ & $\begin{array}{l}\text { Dip. Cruz López Aguilar } \\
\text { (PRI) } \\
08 / 11 / 2011\end{array}$ & $\begin{array}{l}\text { Sin turno a } \\
\text { comisiones } \\
\text { Observación } \\
\text { desechada } \\
\text { 30/04/2013 }\end{array}$ \\
\hline LXI & $4 / 01 / 2012$ & $\begin{array}{l}\text { Ley General de la } \\
\text { Economía Social y Solidaria, } \\
\text { reglamentaria del párrafo } \\
\text { séptimo del artículo } 25 \text { de } \\
\text { la Constitución Política } \\
\text { de los Estados Unidos } \\
\text { Mexicanos por lo que se } \\
\text { refiere al sector social de la } \\
\text { economía }\end{array}$ & $\begin{array}{l}\text { Sen. René Arce Islas } \\
\text { (PVEM) } \\
14 / 09 / 2010\end{array}$ & $\begin{array}{l}\text { Observaciones } \\
\text { aprobadas } \\
23 / 05 / 2012\end{array}$ \\
\hline
\end{tabular}

\section{Nuevo EQUilibrio ENTRE LOS PODERES}

Otro aspecto relevante a analizar en la relación ejecutivo-legislativo son los cambios constitucionales aprobados durante las LX y LXI Legislaturas que modificaron la dinámica entre el presidente y el Congreso. Estos cambios se pueden clasificar en cuatros grandes categorías: 1) las modificaciones que otorgaron más poderes al ejecutivo, 2) los cambios que acotaron los poderes del ejecutivo, 3) las enmiendas constitucionales que otorgaron más facultades al legislativo y, finalmente, 4) cambios que potencialmente modifican las facultades de ambos poderes.

Dentro de la primera categoría está la modificación constitucional al artículo 71, la cual introdujo la figura de iniciativa preferente. ${ }^{48}$ Este instrumento permite al ejecutivo introducir dos

${ }^{48}$ Decreto publicado en el Diario Oficial de la Federación el día 9 de agosto de 2012. 
iniciativas preferentes al inicio de cada periodo legislativo o señalar con tal carácter dos iniciativas que haya presentado en periodos anteriores y estén pendientes de dictamen. La iniciativa preferente le otorga mayor poder de agenda al presidente, ya que obliga a los legisladores a enfocarse a analizar y dictaminar en un breve periodo sus propuestas pues el cambio constitucional establece que cada cámara tiene un plazo máximo de treinta días naturales para discutirlas y votarlas. En caso de no cumplirse con este mandato, la Constitución instruye que la iniciativa preferente sea el primer asunto que se examine y se vote en la siguiente sesión de la cámara en la que se esté discutiendo la propuesta del presidente. El fundamento para introducir este mecanismo fue la supuesta parálisis legislativa de las iniciativas originadas por el ejecutivo, argumento que como se analizó en secciones anteriores es parcialmente cierto, pues la gran mayoría de las propuestas del presidente Calderón fueron dictaminadas y votadas por el Congreso. Como se mencionó previamente, el presidente Calderón hizo uso de esta facultad durante la LXII Legislatura (2012-2015) al presentar como preferentes la iniciativa de reforma a la Ley Federal del Trabajo y la Ley General de Contabilidad Gubernamental.

El presidente también obtuvo mayores atribuciones con la modificación al artículo 88 constitucional. ${ }^{49}$ La nueva redacción otorga al ejecutivo la facultad de ausentarse del territorio nacional hasta por siete días sin autorización previa del Congreso de la Unión. ${ }^{50}$ En materia de política exterior, la reforma constitucional al artículo 89, fracción x, autoriza al presidente a celebrar tratados internacionales así como a denunciar, suspender, modificar, enmendar, retirar reservas y formular declaraciones interpretativas sobre los mismos. ${ }^{51}$ Otro cambio a este mismo artículo (fracción III) otorgó más facultades al ejecutivo para nombrar con aprobación del Senado a los integrantes de los órganos

${ }^{49}$ Loc. cit.

${ }^{50}$ No obstante, el presidente tiene la obligación de informar previamente los motivos de su ausencia al Senado o a la Comisión Permanente. El ejecutivo también debe informar a esta misma cámara las gestiones realizadas durante su viaje. Decreto publicado en el Diario Oficial de la Federación el día 10 de junio de 2011.

${ }^{51}$ Loc. cit. 
reguladores en materia de telecomunicaciones, energía y competencia económica. ${ }^{52}$

Entre los cambios de la segunda categoría, los que acotaron el poder del ejecutivo, está la modificación al artículo 29 de la Constitución. ${ }^{53}$ Este cambio obliga a que los decretos que expida el presidente durante los casos de invasión, perturbación grave o de cualquier otro que ponga a la sociedad en grave peligro o conflicto tengan que ser revisados y validados inmediatamente por la $\mathrm{Su}$ prema Corte de Justicia de la Nación. ${ }^{54}$ Asimismo, los legisladores aprobaron el decreto que reforma el artículo 33, el cual acota la discrecionalidad del presidente para expulsar a un extranjero del país, pues la nueva disposición constitucional obliga al ejecutivo a apegarse a la ley reglamentaria de este artículo. ${ }^{55}$

En la tercera categoría (cambios que otorgaron más facultades al poder legislativo) se encuentra la enmienda constitucional al artículo 76, fracción I, la cual expandió los poderes del Senado de la República en materia de política exterior. ${ }^{56}$ En concreto, el cambio constitucional facultó a los miembros de la cámara alta a terminar, denunciar, suspender, modificar, enmendar, retirar reservas y formular declaraciones sobre los tratados internacionales suscritos por el ejecutivo. Anteriormente, este artículo únicamente facultaba al Senado a aprobar los tratados internacionales. Otra modificación importante en esta categoría son los cambios a los artículos 69 y 93 constitucionales, que dan mayores facultades de control a los legisladores ${ }^{57}$ Entre otros puntos, las reformas otorgan a los diputados y senadores la posibilidad de requerir al ejecutivo información adicional a la presentada en el informe de gobierno mediante preguntas escritas. Asimismo, las modificaciones establecen un plazo máximo de quince días naturales para que los titulares de las dependencias respondan por escrito a las preguntas de los legisladores.

${ }^{52}$ Decreto publicado en el Diario Oficial de la Federación, 9 de agosto de 2012.

${ }^{53}$ Decreto publicado en el Diario Oficial de la Federación, 10 de junio de 2011.

${ }^{54}$ Decreto publicado en el Diario Oficial de la Federación, 10 de junio de 2011.

55 Loc. cit.

${ }^{56}$ Decreto publicado en el Diario Oficial de la Federación, 12 de febrero de 2007.

${ }^{57}$ Decreto publicado en el Diario Oficial de la Federación, 15 de agosto de 2008. 
TABLA 5

Reformas constitucionales aprobadas durante las LX y LXI Legislaturas que establecen un nuevo equilibrio entre los poderes ejecutivo y legislativo

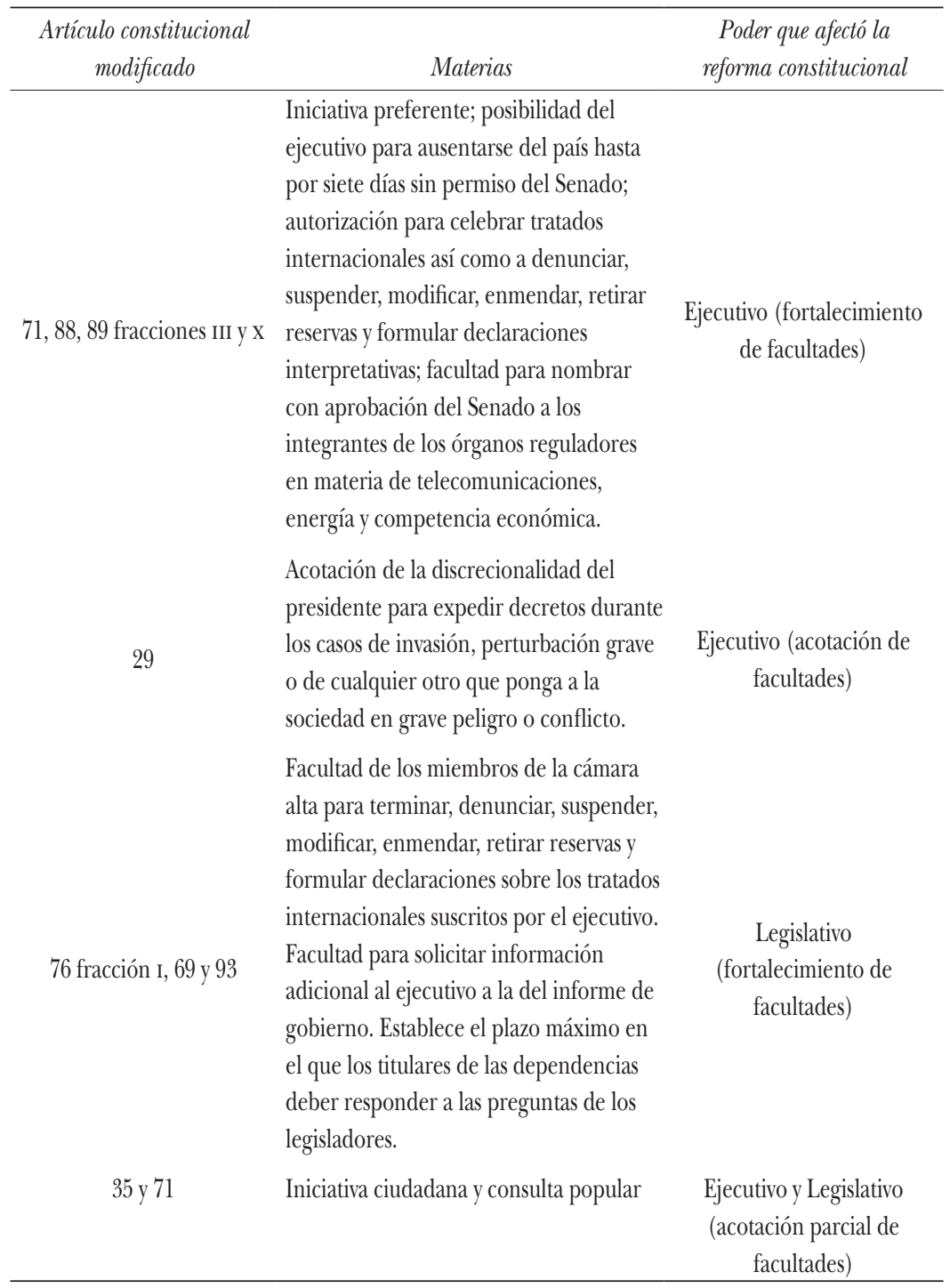


Finalmente, en la cuarta categoría -los decretos que modificaron las facultades tanto del ejecutivo como del legislativo- resaltan dos cambios importantes. El primero fue la expansión de derechos del ciudadano (artículo 35 y 71). ${ }^{58}$ Concretamente, las nuevas estipulaciones otorgan a la ciudadanía la posibilidad de iniciar leyes ante el Congreso de la Unión si reúnen $0.13 \%$ de la lista nominal de electores. Aunque el umbral legal para introducir este tipo de iniciativas es alto, y por lo tanto difícil de conseguir, sí otorga poder a los ciudadanos para que el Congreso de la Unión preste atención a sus propuestas. La posibilidad de que la ciudadanía pueda presentar iniciativas de ley transforma en cierta medida las facultades tanto del Congreso, el ejecutivo y las Legislaturas de los Estados, ya que abre la posibilidad para que un nuevo jugador participe en la agenda legislativa. La segunda modificación fue el cambio a la fracción viI del mismo artículo, la cual posibilita a la ciudadanía pedir una consulta popular sobre un tema de trascendencia nacional si ésta es solicitada por el dos por ciento de los ciudadanos inscritos de la lista nominal de electores. ${ }^{59}$ Más aún, el cambio constitucional prevé que la consulta ciudadana tenga efectos vinculantes si existe una participación de al menos $40 \%$ de los ciudadanos inscritos en la lista nominal de electores. Esta modificación también puede transformar la dinámica entre el ejecutivo y el legislativo, pues abre la posibilidad de que los ciudadanos cambien alguna disposición transcendente para el país aun cuando alguno o los dos poderes se opusieran.

El análisis de las cuatro categorías arriba presentadas sugiere que aunque todos los cambios constitucionales aprobados durante la gestión del presidente Calderón pueden tener un efecto en la relación entre el ejecutivo y el legislativo, la iniciativa preferente y la consulta popular pueden ser los que más impacto tengan

\footnotetext{
${ }^{58}$ Decreto publicado en el Diario Oficial de la Federación el día 9 de agosto de 2012.

${ }^{59}$ El presidente de la República o el $33 \%$ de los integrantes de cualquiera de las cámaras también pueden pedir que el Congreso de la Unión convoque a una consulta popular. A diferencia del caso de la ciudadanía, la petición de consulta popular tanto del presidente como de los legisladores tiene que ser aprobada por una mayoría en cada cámara.
} 
en la relación entre los dos poderes. ${ }^{60}$ Aunque aún no ha pasado el tiempo suficiente que permita observar los efectos de estos cambios constitucionales, es probable que en los años siguientes ocurran cambios a distintas materias de política pública por medio de estos instrumentos. La tabla 5 resume las modificaciones señaladas.

\section{LA APROBACIÓN DE LAS REFORMAS ESTRUCTURALES AL INICIO del SeXenio del PResidente PeÑa Nieto}

Durante los primeros veinte meses del gobierno del presidente Enrique Peña Nieto fueron aprobadas las reformas estructurales que habían permanecido varios años estancadas en el Congreso de la Unión. Aunque once reformas de gran envergadura se aprobaron en este periodo, en estricto sentido sólo siete fueron de corte estructural. Estas reformas son: energética, hacendaria, telecomunicaciones, competencia económica, financiera, educativa y laboral. ${ }^{61}$

${ }^{60}$ Un análisis completo de los efectos de los cambios constitucionales recientes en la relación entre el poder ejecutivo y el legislativo debe incluir las modificaciones realizadas durante el primer año de gestión del presidente Enrique Peña Nieto entre las que sobresale la reelección legislativa consecutiva, la autonomía de varios órganos reguladores y la transformación de la Procuraduría General de la República en la Fiscalía General de la República.

${ }^{61}$ Las reformas estructurales son aquellas políticas que reducen o remueven los impedimentos para la eficiente distribución de los recursos incrementando así el nivel promedio de ingreso. Entre las medidas establecidas por las reformas estructurales están las que disminuyen la intervención gubernamental -tales como la remoción de los controles de precios y la abolición de los monopolios estatalesy las que están orientadas a corregir las distorsiones del mercado no producidas por la intervención del gobierno. Véase International Monetary Fund, "Structural Reforms and Economic Performance in Advanced and Developing Countries", IMF Policy Paper, Washington, International Monetary Fund, 2008, pp. 1-49. Los otros cuatro cambios de gran envergadura aprobados durante este periodo fueron la creación del Código Nacional de Procedimientos Penales, la Ley de Amparo, la reforma politica-electoral y las modificaciones a la ley transparencia. Aunque relevantes, estas modificaciones no están orientadas directamente a generar mayor crecimiento económico por lo que no son consideradas como reformas estructurales. 
Como se mencionó con anterioridad, varias de estas reformas no pudieron convertirse en leyes tanto en el sexenio del presidente Calderón como en gobiernos anteriores. El ejemplo más emblemático es la reforma energética. Desde la administración del presidente Ernesto Zedillo se realizaron intentos por hacer modificaciones a la Constitución para abrir este sector a la inversión privada, los cuales sin embargo no encontraron resonancia en el poder legislativo. Como se documentó en secciones previas, durante el sexenio del presidente Calderón se aprobaron algunos cambios en materia energética. No obstante, el principal objetivo de la iniciativa del ejecutivo -aperturar el sector energético a inversionistas privadosfue rechazada por los partidos de oposición en el Congreso. En contraste, a la presente administración le bastó poco más de año y medio para ver promulgada ésta y otras importantes reformas.

Para explicar la ausencia de consenso en las reformas estructurales, algunos autores establecieron como causas el efecto de ciertas reglas institucionales, el avance de la pluralidad política en el país y la presión de actores sociales y económicos por mantener el statu quo. ${ }^{62}$ Por ejemplo, Carlos Elizondo argumentó que las reformas estructurales permanecían estancadas debido a su la alta impopularidad y a algunas reglas institucionales como el sistema electoral y la prohibición de la reelección legislativa consecutiva. Estos factores, de acuerdo a este autor, tienden a producir gobiernos sin mayoría, tripartidismo, inhiben el surgimiento de nuevas fuerzas políticas que empujen una agenda legislativa modernizadora y favorecen que los legisladores respondan a sus dirigencias partidistas y no a los ciudadanos. ${ }^{63}$ Por lo tanto, dado que México tiene un sistema presidencial dominado por tres partidos, con gobiernos sin mayoría desde 1997 y que no contaba con la posibilidad de que sus legisladores fueran reelectos consecutivamente, se

62 Véase, por ejemplo, María Amparo Casar, "Representation and DecisionMaking in the Mexican Congress", en Moira B. MacKinnon y Ludovico Feoli (eds.), Representation and Effectiveness in Latin American Democracies, Nueva York, Routledge, 2013, pp. 91-110; Casar, "Quince años de gobiernos sin mayoría en el Congreso mexicano", op. cit.; Magar y Romero, "El impasse mexicano en perspectiva”, op. cit., y Elizondo, Por eso estamos como estamos, op. cit.

${ }^{63}$ Elizondo, op. cit. 
consideraba que la aprobación de reformas estructurales era extremadamente improbable.

Aunque teóricamente sólidas, estas explicaciones perdieron poder explicativo al aprobarse las reformas estructurales, dado que el marco institucional y el contexto político fueron los mismos que cuando no se logró concretar estas modificaciones. Si las separaciones de propósito (sistema presidencial), de poder (gobierno sin mayoría) y las reglas institucionales permanecieron constantes, ¿qué factores permitieron la reciente aprobación de las modificaciones de gran calado? Aunque el análisis de las causas que dieron paso a la aprobación de las reformas estructurales rebasa los objetivos de este texto, a continuación se esbozan tres factores que facilitaron la consecución de dicho objetivo.

\section{La luna de miel y el Pacto por México}

El comienzo de las administraciones generalmente es el momento ideal para que los presidentes presenten iniciativas que impliquen cambios estructurales. Durante este periodo, conocido como "la luna de miel", los presidentes generalmente gozan de alta aprobación ciudadana y existe la expectativa en buena parte de la opinión pública de que el nuevo gobierno resolverá los grandes problemas que afectan al país. ${ }^{64}$ Por otra parte, la luna de miel tiende a ser un periodo de baja tensión política, pues no hay comicios electorales en puerta y por lo tanto la polarización entre los partidos es baja. En consecuencia, durante los primeros meses de su gobierno los presidentes se encuentran ante un contexto favorable para impulsar iniciativas de ley que transformen a profundidad varias áreas de política pública; hay además una tendencia de la ciudadanía, medios y la clase política a ser más receptivos a las acciones de la nueva adminstración.

${ }^{64}$ La bibliografía en ciencia política norteamericana ha estudiado a profundidad la luna de miel de los presidentes en los Estados Unidos. Véase por ejemplo Richard A. Brody, Assessing the President: The Media, Elite Opinion, and Public Support, California, Stanford University Press, 1991. 
En el caso del sexenio anterior, el presidente Calderón no tuvo la ventana de oportunidad que le da la luna de miel para presentar al Congreso las reformas estructurales a causa de la polarización política existente en ese momento. El conflicto poselectoral y el discurso del no reconocimiento de la izquierda a Felipe Calderón como titular del poder ejecutivo no propiciaron un ambiente favorable para que se introdujeran en el Congreso las reformas de gran calado. Es probable que la polarización política hubiera crecido significativamente si el presdiente Calderón hubiese mandado este tipo de iniciativas al Congreso al inicio de su administración.

En contraste, aunque no exento de conflicto poselectoral, el presidente Peña comenzó su sexenio en condiciones políticas más favorables que las de su antecesor, lo cual facilitó la presentación y aprobación de las siete reformas estructurales antes mencionadas con sus respectivas leyes secundarias. Además de que el tiempo fue oportuno, otro elemento que explica la aprobación de las reformas estructurales fue la creación del Pacto por México. Éste fue un acuerdo nacional firmado el 1 de diciembre de 2012 entre el presidente Peña y los presidentes de los tres partidos políticos con más arraigo en el país (PRI, PAN Y PRD). Mediante este instrumento, el presidente y las fuerzas políticas acordaron una agenda de gobierno en común de la cual se derivaron 95 acciones administrativas e iniciativas de ley. ${ }^{65}$ Aunque el Pacto por México llegó a su fin un año después de su firma y no logró concretar todos sus compromisos, sí consiguió articular las coaliciones legislativas mínimas para la aprobación de las reformas estructurales que estuvieron estancadas por varios años. ${ }^{66}$

${ }^{65}$ La agenda del Pacto por México indica que sus firmantes estaban conscientes de la importancia del timing en que se debían presentar y aprobar las reformas: la gran mayoría de los compromisos establecidos fueron calendarizados para ratificarse por el Congreso durante el primer año del sexenio.

${ }^{66}$ El Pacto por México se disolvió en diciembre de 2013, cuando el PRD se retiró debido a que consideró que la iniciativa de reforma energética acordada por el PRI y el PAN sobrepasó lo previamente estipulado entre los partidos. Con excepción de la reforma laboral, la cual fue aprobada durante el periodo de transición entre los presidentes Calderón y Peña, todas las reformas estructurales estu- 
El que el presidente y la oposición consensuarán una agenda legislativa que incluyera las reformas estructurales fue un hecho inusual en la política mexicana, pues la experiencia reciente indica que el ejecutivo era el encargado de presentar ante el Congreso este tipo de iniciativas. Dado el contexto de gobierno sin mayoría, al presidente Peña le hubiera sido muy difícil aprobar por sí solo estas modificaciones, por lo que decidió ser parte del Pacto y así compartir en buena medida su papel como principal impulsor de la transformación del país con el PAN y el PRD. En otras palabras, la aprobación del paquete de reformas estructurales se debió en gran medida a que éstas fueron presentandas en un momento oportuno y a que el presidente compartió el crédito de modernizador de México con las dos principales fuerzas políticas. ${ }^{67}$

\section{Liderazgo}

Otro factor que explica por qué durante el inicio de la administración del presidente Peña fue posible aprobar el conjunto de reformas estructurales es el liderazgo de los actores que participaron en el Pacto por México. La capacidad política de los integrantes de este acuerdo queda evidenciado cuando se contrasta con la habilidad de negociación de los políticos de las administraciones anteriores. Por ejemplo, el presidente Fox, a pesar de contar con alta popularidad al inicio de su sexenio, fue incapaz de construir una coalición legislativa estable que le permitiera pasar iniciativas de

vieron incluidas en la agenda del Pacto. No obstante, algunas de estas reformas -como la energética o la hacendaria- fueron ratificadas por coaliciones legislativas en las que no participaron alguno de los partidos de oposición integrantes de este acuerdo (PAN O PRD).

${ }^{67}$ Tal vez ésta es la razón por la que la gestión del presidente Peña no obtuvo más de $62 \%$ de aprobación de la opinión pública en su primer año de gobierno. Véase Parametría, "Carta Paramétrica: Enrique Peña Nieto a un año de gestión”, 25 de noviembre de 2013, http://www.parametria.com.mx/carta_parametrica. php?cp=4601 
gran calado en el Congreso. ${ }^{68}$ Gran parte su agenda (incluidas las reformas hacendaria, energética y laboral) quedó estancada, entre otros factores, por la confrontación que tuvo con los grupos parlamentarios de oposición. La estrategia del mandatario panista de dirigirse directamente a la población para presionar a los legisladores a que pasaran su agenda no prosperó. ${ }^{69}$ Por su parte, en el caso del segundo sexenio panista, además del alto nivel de polarización política que caracterizó al gobierno del presidente Calderón, algunas de sus acciones dificultaron la construcción de alianzas con los partidos de oposición. Por ejemplo, la detención de once presidentes municipales en Michoacán en mayo de 2009 produjo gran molestia entre los líderes de oposición, pues se realizó con escasas evidencias y pocos días antes de la elección intermedia. Este hecho complicó el apoyo a la agenda del ejecutivo. La oposición veía una doble señal: por un lado el presidente les solicitaba su voto en el Congreso y por otro percibían que los golpeaba políticamente. ${ }^{70}$

En contraste, los integrantes del Pacto por México no sólo fueron hábiles para incluir puntos esenciales de sus plataformas en la agenda de este acuerdo, sino también para mantenerlo durante un año. El presidente Peña fue muy cuidadoso de las formas para

${ }^{68}$ En febrero de 2001 Vicente Fox contaba con $70 \%$ de aprobación ciudadana a su gestión. Véase Alejandro Moreno y Roberto Gutiérrez, "Encuesta/Marca 'Elbazo' primeros meses”, Reforma, 1 de abril de 2013, p. 4. De acuerdo con Santiago Creel, la falta de liderazgo político fue el motivo del fracaso del Acuerdo Político para el Desarrollo Nacional firmado por el presidente Fox y todas las fuerzas opositoras en octubre de 2001. Según el panista, el cual fungía como secretario de gobernación en ese momento, la presidenta del PRI, Dulce María Sauri, no consiguió que los líderes priistas en las cámaras ni los gobernadores de su partido apoyaran dicho acuerdo. Véase Denise Maerker, "La historia del Pacto por México", Punto de Partida, 13 de agosto de 2013.

${ }^{69}$ Stephen Haber, Herbert S. Klein, Noel Maurer, Kevin J. Middlebrook, Mexico since 1980, Nueva York, Cambridge University Press, 2008, p. 157.

${ }^{70}$ Para abril de 2011 todos los presidentes municipales detenidos habían sido liberados por falta de pruebas. Véase Francisco Reséndiz, "PGR hizo ridículo por michoacanazo: Ortega", El Universal, 29 de septiembre de 2010, http:/ /www.eluni versal.com.mx/notas/712579.html 
salvaguardar la unidad del Pacto. ${ }^{71}$ La atención que le prestó fue visible tanto en los discursos presidenciales como en los comunicados del gobierno federal, en los cuales siempre enfatizó que el origen de las iniciativas no era un partido o un actor político, sino el Pacto. ${ }^{72}$ El único traspié que el ejecutivo cometió fue cuando brindó apoyo a la secretaria de Desarrollo Social al darse a conocer las acusaciones sobre el uso indebido de recursos públicos federales de esta dependencia en Veracruz. Sin embargo, este error se subsanó con el adenda al Pacto y la remoción de algunos funcionarios involucrados en este presunto ilícito. ${ }^{73}$

Por su parte, los dirigentes del PAN y el PRD no sólo demostraron su capacidad negociadora al conseguir que varias de sus propuestas se incluyeran en la agenda del Pacto, sino también al lograr acotar algunas facultades al ejecutivo. Por ejemplo, algunas reformas otorgaron la autonomía a ciertas agencias gubernamentales que anteriormente se encontraban bajo control directo o indirecto del presidente, como es el caso de Comisión Federal de Competencia Económica. El liderazgo de la oposición también se evidenció al contener las resistencias intrapartidistas que se oponían a la cooperación con el gobierno y al conseguir los votos necesarios en el Congreso para aprobar los dictámenes legislativos. En suma, el agendar la aprobación de las reformas estructurales durante los primeros meses de la administración priista, la creación del Pacto por México y la capacidad de liderazgo de los líderes políticos fueron los factores y condiciones que permitieron la aprobación de las reformas estructurales.

71 Carlos Elizondo enfatiza el factor del liderazgo político en la aprobación de las reformas estructurales al argumentar que "La debilidad del presidente no era por el gobierno dividido, sino por la incapacidad de quienes se sentaban en la silla. Hoy se aprueban reformas impensables". Véase Carlos Elizondo, "Politólogos inútiles", Reforma, 25 de abril de 2013, p. 17.

72 Véase, por ejemplo, Enrique Peña Nieto, "Un nuevo México", El País, 24 de agosto de 2014, http:/ / elpais.com/elpais/2014/08/20/opinion/1408541903_825 803.html

${ }^{73}$ Véase Marcela Turati, “Destituye Sedesol a siete 'mapaches electorales' en Veracruz", Proceso, 18 de abril de 2013, http:/ /www.proceso.com.mx/?p=339371 


\section{Conclusiones}

Dada la separación de poder característica de los sistemas presidenciales, los poderes ejecutivo y legislativo tienen que negociar permanentemente la aprobación de la agenda legislativa. Aun cuando el presidente obtiene una mayoría en el Congreso, el ejecutivo tiene que acercarse a los legisladores para conseguir ciertos objetivos de política pública, como es el caso de cambios que requieren reformas a la Constitución. La reflexión en ciencia política ha establecido que los sistemas presidencialistas multipartidistas provocan confrontación entre el ejecutivo y el legislativo. En principio, se argumenta que, a menos que se establezca un gobierno de coalición, el ejecutivo tendrá dificultades para aprobar su agenda, pues cada poder es electo de manera separada y ejercen su autoridad independientemente del otro. ${ }^{74}$

El análisis de las relaciones ejecutivo-legislativo durante la gestión del presidente Calderón demuestra que la expectativa teórica de constante conflicto entre los poderes y la parálisis legislativa es parcialmente cierta. Como se documenta en secciones anteriores, el ejecutivo tuvo una tasa de aprobación de su agenda de gobierno bastante alta, incluso bajo factores adversos como la alta polarización política y la ausencia de una mayoría parlamentaria en ambas cámaras. Asimimso, el presidente Calderón pudo pasar importante legislación que sí alteró el statu quo vigente en diversas áreas de política pública. No obstante, el ejecutivo no fue capaz de conseguir el apoyo necesario para aprobar las llamadas reformas estructurales que sólo hasta hace poco fueron aprobadas por el Congreso de la Unión.

La falta de acuerdo entre el ejecutivo y los legisladores para sacar adelante las reformas de gran calado contribuyó a que se formara la percepción de un enfrentamiento continuo entre el presidente y el Congreso. Aunque algunos politólogos afirmaron que las causas

${ }^{74}$ Juan J. Linz, "Presidential or Parliamentary Government: Does It Make a Difference?, op. cit. Para una revisión de la discusión reciente en este tema, véase Matthew Soberg Shugart, "Comparative Executive-Legislative Relations”, en Sarah A. Binder, R. A.W. Rhodes y Bert A. Rockman (eds.), The Oxford Handbook of Political Institutions, Nueva York, Oxford University Press, 2008, pp. 344-365. 
de la no aprobación de las reformas importantes eran factores institucionales y contextuales como el avance democrático, los gobiernos sin mayoría y el veto de grupos de poder, el análisis de la relación entre el ejecutivo-legislativo durante el sexenio del presidente Calderón debilita dichos argumentos. Como se documentó en este texto, varias iniciativas relevantes se convirtieron en leyes entre 2006 y 2012. Asimismo, el hecho de que las reformas estructurales se aprobaron en 2013 bajo el mismo marco institucional y contexto político que en las administraciones anteriores sugiere que no son las variables institucionales sino otro tipo de factores -tales como el timing, la creación de acuerdos políticos estables y la capacidad de liderazago- los que pueden dar mejor cuenta de la falta de aprobación de los cambios de gran envergadura.

Por otra parte, no se observa que los vetos presidenciales hayan causado mayor conflicto entre los dos poderes. El número de observaciones interpuestas por el presidente Calderón fue muy bajo en relación a número de decretos aprobados por el Congreso. Asimismo, la aceptación de varias de las observaciones por los legisladores y el desistimiento para revocarlos sugieren que la utilización de esta herramienta no dañó significativamente la relación ejecutivo-legislativo. Por último, el consenso para la aprobación de varias modificaciones constitucionales que alteraron el equilibrio entre los dos poderes indica que en general hubo más colaboración que conflicto entre el presidente y el Congreso durante este sexenio.

\section{BibLIOGRAFÍA}

Becerril, Andrea y Georgina Saldierna, "Deja Ricardo Monreal fracción del PRD en el Senado y se integra a la del PT", La Jornada, 12 de diciembre de 2008, http://www.jornada.unam.mx/2008/12/12/index.php ?section=politica\&article $=018 \mathrm{n} 1 \mathrm{pol}$

Binder, Sarah A., "Legislative Productivity and Gridlock", en Eric Schickler y Frances E. Lee (eds.), The Oxford Handbook of American Congress, Nueva York, Oxford University Press, 2011, pp. 641-660.

, "The Dynamics of Congressional Gridlock", American Political Science Review, vol. 93, núm. 3, 1999, pp. 519-533. 
Brody, Richard A., Assessing the President: The Media, Elite Opinion, and Public Support, California, Stanford University Press, 1991.

Casar, María Amparo, "Quince años de gobiernos sin mayoría en el Congreso mexicano”, Política y Gobierno, vol. 20, núm. 2, 2013, pp. 219263.

, "Representation and Decision-Making in the Mexican Congress", en Moira B. MacKinnon y Ludovico Feoli (eds.), Representation and Effectiveness in Latin American Democracies, Nueva York, Routledge, 2013, pp. 91-110.

_ e Ignacio Marván, "Pluralismo y reformas constitucionales", en María Amparo Casar e Ignacio Marván (coords.), Reformar sin mayorías, México, Taurus, 2014, pp. 13-85.

Chiou, Fang y Lawrence S. Rothenberg, "Comparing Legislators and Legislatures: The Dynamics of Legislative Gridlock Reconsidered", Political Analysis, vol. 16, núm. 2, 2008, pp. 197-212.

Cohen, Jeffrey, The President's Legislative Policy Agenda 1789-2002, Nueva York, Cambridge University Press, 2012.

Cox, Gary W. y Mathew McCubbins, "The Institutional Determinants of Economic Policy Outcomes”, en Stephan Haggard y Mathew D. McCubbins (eds.), Presidents, Parliaments, and Policy, Nueva York, Cambridge University Press, 2001, pp. 21-63.

Edwards, George, III, The Strategic President, Princeton, Princeton University Press, 2009.

, Andrew Barrett y Jeffrey Peake, "The Legislative Impact of Divided Government”, American Journal of Political Science, vol. 41, núm. 2, 1997, pp. 545-563.

Elgie, Robert, "What is Divided Government?", en Robert Elgie (ed.), Divided Government in Comparative Perspective, Nueva York, Oxford University Press, 2001, pp. 1-20.

Elizondo, Carlos, Por eso estamos como estamos, México, Debate, 2011. -, "Politólogos inútiles", Reforma, 25 de abril de 2013, p. 17.

"Firman Ley de Víctimas", Reforma, 9 de enero de 2013.

Gibson, Martha, "Politics and Divided Government", artículo presentado en reunión anual de la American Political Science Association, Nueva York, 1994.

Gormley William T., Jr., y Steven J. Balla, Bureaucracy and Democracy, tercera edición, Thousand Oaks, California, CQ Press, 2013. 
Guerrero, Claudia, "Jalan reforma política Gobierno y Senado", Reforma, 17 de octubre de 2013, p. 11.

- y Érika Hernández, "Avalan en el Senado nueva era de Pemex", Reforma, 24 de octubre de 2008, p. 6.

— Érika Hernández y Claudia Salazar, "Sesionan en el caos”, Reforma, 2 de diciembre de 2006, p. 6.

Haber, Stephen, Herbert S. Klein, Noel Maurer, Kevin J. Middlebrook, Mexico since 1980, Nueva York, Cambridge University Press, 2008.

Heitshusen, Valerie y Garry Young, "Macropolitics and Changes in the U.S. Code: Testing Competing Theories of Policy Production, 18741946”, en E. Scott Adler y John S. Lapinski (eds.), The Macropolitics of Congress, Princeton, Princeton University Press, 2006, pp. 129-150.

Howell, William, Scott Adler, Charles Cameron y Charles Riemann, "Divided Government and the Legislative Productivity of Congress 19451994”, Legislative Studies Quarterly, vol. 25, núm. 2, 2000, pp. 285-312.

Huber, John y Charles R. Shipan, Deliberate Discretion?, Nueva York, Cambridge University Press, 2002.

International Monetary Fund, "Structural Reforms and Economic Performance in Advanced and Developing Countries", IMF Policy Paper, Washington, International Monetary Fund, 2008, pp. 1-49.

Jones, Charles O., The Presidency in a Separated System, Washington, D. C., Brookings Institution, 1994.

Kelly, Sean, "Divided We Govern? A Reassessment", Polity, vol. 25, núm. 3, 1993, pp. 475-484.

Key, Valdimer Orlando, Politics, Parties, and Pressure Groups, Nueva York, Thomas Y. Crowell Company, 1964.

Krause, George, "Legislative Delegation of Authority to Bureaucratic Agencies", en Robert F. Durant (ed.), The Oxford Handbook of American Bureaucracy, Nueva York, Oxford University Press, 2010, pp. 521-544.

Linz, Juan J., "Presidential or Parliamentary Government: Does It Make a Difference?”, en Juan J. Linz y Arturo Valenzuela (eds.), The Failure of Presidential Democracy, vol. 1: Comparative Perspectives, Baltimore, The Johns Hopkins University Press, 1994, pp. 3-90.

Maerker, Denise, "La historia del Pacto por México", Punto de Partida, 13 de agosto de 2013.

Magar, Eric y Vidal Romero, "El impasse mexicano en perspectiva”, Foreign Affairs en Español, vol. 7, núm. 1, 2007, pp. 117-131. 
Mayhew, David, Divided We Govern: Party Control, Lawmaking, and Investigations 1946-2002, New Haven, Yale University Press, 2005.

Moreno, Alejandro y Roberto Gutiérrez, "Encuesta/Marca 'Elbazo' primeros meses", Reforma, 1 de abril de 2013, p. 4.

Miller, Gary, "The Political Evolution of Principal-Agent Models", Annual Review of Political Science, vol. 8, 2005, pp. 203-225.

Neustadt, Richard, Presidential Power and the Modern Presidents, Nueva York, The Free Press, 1990.

Parametría, "Carta Paramétrica: Enrique Peña Nieto a un año de gestión”, 25 de noviembre de 2013, http://www.parametria.com.mx/carta_pa rametrica.php?cp $=4601$

Peña Nieto, Enrique, "Un nuevo México", El País, 24 de agosto de 2014, http:/ / elpais.com/elpais/2014/08/20/opinion/1408541903_82580 3.html

Rogers, James, “The Impact of Divided Government on Legislative Production”, Public Choice, vol. 123, núms. 1-2, 2005, pp. 217-233.

Shipan, Charles, "Congress and the Bureaucracy", en Paul J. Quirk y Sarah A. Binder (eds.), The Legislative Branch, Nueva York, Oxford University Press, 2005, pp. 432-458.

Shugart, Matthew Soberg, "Comparative Executive-Legislative Relations", en Sarah A. Binder, R.A.W. Rhodes y Bert A. Rockman (eds.), The Oxford Handbook of Political Institutions, Nueva York, Oxford University Press, 2008, pp. 344-365.

Shugart, Matthew Soberg y Stephen Haggard, "Institutions and Public Policy in Presidential Systems", en Stephan Haggard y Mathew D. McCubbins (eds.), Presidents, Parliaments, and Policy, Nueva York, Cambridge University Press, 2001, pp. 64-102.

Sundquist, James, "Needed: A Political Theory for the New Era of Coalition Government in the United States", Political Science Quarterly, vol. 103, núm. 4, invierno 1988-1989, pp. 613-635.

Turati, Marcela, "Destituye Sedesol a siete 'mapaches electorales' en Veracruz”, Proceso, 18 de abril de 2013, http://www.proceso.com.mx/? $\mathrm{p}=339371$

Wood, Dan B., "Agency Theory and the Bureaucracy", en Robert F. Durant (ed.), Oxford Handbook of American Bureaucracy, Nueva York, Oxford University Press, 2010, pp. 181-206. 